\title{
On the Bullwhip Avoidance Phase: The Synchronised Supply Chain
}

\author{
Elena Ciancimino ${ }^{\mathrm{a}, *}$, Salvatore Cannella $^{\mathrm{b}}$, Manfredi Bruccoleri ${ }^{\mathrm{a}}$, Jose M. Framinan ${ }^{\mathrm{c}}$ \\ a Department of Chemical, Management, Mechanical Engineering and Computer Science, University of Palermo, Palermo, Italy \\ ${ }^{\mathrm{b}}$ Centre for Management Studies, Instituto Superior Técnico, Technical University of Lisbon, Porto Salvo, Portugal \\ ${ }^{\mathrm{c}}$ Industrial Management, School of Engineering, University of Seville, Seville, Spain
}

\section{A R T I C L E I N F O}

Article history:

Received 30 April 2009

Accepted 28 February 2012

Available online 5 March 2012

\section{Keywords:}

Inventory

Supply chain management

Simulation

Collaboration

Information sharing

\begin{abstract}
A B S T R A C T
The aim of this paper is to analyse the operational response of a Synchronised Supply Chain (SSC). To do so, first a new mathematical model of a SSC is presented. An exhaustive Latin Square design of experiments is adopted in order to perform a boundary variation analysis of the main three parameters of the periodic review smoothing $(S, R)$ order-up-to policy: i.e., lead time, demand smoothing forecasting factor, and proportional controller of the replenishment rule. The model is then evaluated under a variety of performance measures based on internal process benefits and customer benefits. The main results of the analysis are: (I) SSC responds to violent changes in demand by resolving bullwhip effect and by creating stability in inventories under different parameter settings and (II) in a SSC, long productiondistribution lead times could significantly affect customer service level. Both results have important consequences for the design and operation of supply chains.
\end{abstract}

(c) 2012 Elsevier B.V. All rights reserved.

\section{Introduction}

The so-called Bullwhip effect, i.e., the amplification of demand variability from a downstream site to an upstream site, has been observed throughout industry for many years, and it has been regarded as one of the forces that paralyse supply chains (Lee et al., 1997). This term has been also used to describe the distortion of information from one part of the supply chain to another, the distortion of consumption pattern from the ordering pattern at a firm, or, simply put, "What you see is not what they (your customer) face” (Lee et al., 2006).

Extensive research has been conducted to identify the operational causes of the bullwhip effect (Ouyang and Daganzo, 2008), such as disintegrated material flow, distorted demand information and lack of replenishment rule alignment (see e.g. Disney and Lambrecht, 2008). The present era of research on this deleterious phenomenon has thus focused on strategies aimed at preventing the bullwhip effect from occurring and it has been labelled as Bullwhip Avoidance Phase (Holweg and Disney, 2005). Among these strategies, the implementation of supply chain collaboration practices has been advocated in several studies as an effective approach for limiting the bullwhip effect (see e.g. Chen et al., 2000; Disney and Towill, 2002; Chatfield et al., 2004; Shang et al., 2004; Kim et al., 2006; Agrawal et al., 2009; Chen and Lee, 2009; Cannella and Ciancimino, 2010).

\footnotetext{
* Corresponding author.

E-mail addresses: elena.ciancimino@unipa.it (E. Ciancimino), salvatore.cannella @ist.utl.pt (S. Cannella), manfredi.bruccoleri@unipa.it (M. Bruccoleri), framinan@ us.es (J.M. Framinan).
}

From an operational viewpoint, supply chain collaboration materialises in the alignment of planning, forecasting and replenishment systems among partners. Such alignment is enabled by the exchange of information in the supply chain and is aimed at the global optimisation of the network. The paradigm of collaboration at the operational level can be summarised with the concept of "synchronisation of supply chain operations", meaning the replacement of sequential decision-making on replenishment by a single decision that simultaneously considers all relevant inventory and demand information. This emerging supply chain archetype was labelled as Synchronised Supply Chain (SSC) (Anderson and Lee, 1999).

Even though the supply chain literature frequently emphasises the virtues and benefits of collaboration, the issue of synchronisation in supply chains has not been yet thoroughly addressed. Theoretical contributions on collaboration (Lee, 2000; McLaren et al., 2002; Derrouiche et al., 2008; Simatupang and Sridharan, 2008; de Leeuw and Fransoo, 2009; Squire et al., 2009; Stadtler, 2009; Verstrepen et al., 2009; Cannella et al., 2010b) as well as empirical studies (Akintoye et al., 2000; Hahn et al., 2000; Barratt and Oliveira, 2001; Lee, 2004; Vereecke and Muylle, 2006; Pramatari, 2007; Fawcett et al., 2008; Kauremaa et al., 2009; Coleman, 2010) have been the main contributions up to now. There is a need of unambiguous understanding of "which" specific data should be shared, and "how" and "when" these data should be used in order to synchronise the replenishment among companies. Furthermore, to the best of our knowledge, we are not aware of a quantification of the benefits of the synchronisation for the members in a SSC. 
Motivated by such observations, the aim of our work is twofold:

1. First, we attempt to formalise how supply chain members' inventory and replenishment decision have to be linked and what information has to be shared in order to effectively enable the synchronisation of operations. We present a mathematical model for order synchronisation in a SSC. We derive a periodic review order quantity for a SSC and define explicitly the information to be shared for inventory and planning collaboration.

2. Second, we quantify the SSC response to variations of its operational parameters in terms of bullwhip reduction, inventory stability and customer service level. We evaluate the model under a variety of performance measures and using an exhaustive design of experiments by means of a standard Latin Square Design. The adopted system assesses the operational performance or "internal process benefits" (Order Rate Variance Ratio, Inventory Variance Ratio, Bullwhip Slope, Inventory Instability Slope) and evaluates the "customer benefits" (Fill Rate). We study different parameter settings of the supply chain under a sudden and intense change in demand. The different settings are generated by variation on three levels of three key variables of production-inventory control systems, namely lead time, demand forecast factor, and proportional controller of the replenishment rules.

The results of this study show that synchronisation eliminates the bullwhip effect and creates stability in inventories under different parameter settings, thus avoiding the problem of amplifying signals in multi-echelon production and distribution. More specifically, Inventory Variance Ratio curves present a negative slope in the SSC, in contrast with other supply chain archetypes presented in literature. Such negative slope indicates that the variance of the inventory at the manufacturer is lower than the variance of retailer's inventory, which implies that the inventory holding costs increase as we move downstream in the supply chain. The analysis also reveals that, while the impact of varying demand smoothing forecasting factor and proportional controller is not significant on supply chain performance, decreasing lead times always improves the performance. As a consequence, successful lead time management emerges as a key factor for gaining internal and customer benefits in a SSC.

The paper is organised as follows. In Section 2 we discuss the background of our work. Section 3 presents a conceptual model and the equations for orders and material flow in a SSC for the periodic review $(S, R)$ replenishment rule. Section 4 presents the metrics for performance evaluation. In Section 5 the design of experiments and the numerical output are reported. Section 6 present and discusses the results while Section 7 provides conclusions.

\section{Related literature}

This section delineates the context from which this study emerges. Section 2.1 provides an overview on the existing literature about supply chain synchronisation whereas previous analyses on the components of inventory control are reported in Section 2.2 .

\subsection{Synchronised Supply Chain: The evolving frontier of collaboration}

The benefits of inventory and planning collaboration between customer and provider are well-documented since Magee's (1958) and Clark and Scarf's (1960) works. More specifically, Clark and Scarf's paper is regarded as the seminal work in multi-echelon inventory analysis (Whang, 1995; Dong and Lee, 2003; Swaminathan and Tayur, 2003; DeCroix, 2006) and could be reasonably considered the first mathematical formalisation for a fully coordinated decision-making approach (Sahin and Robinson, 2005).

The synchronisation paradigm appeared in literature at the end of the XX century. Anderson and Lee (1999) identified the three major structural changes of the post 2000 era supply chain strategy, design and operations, namely: (I) Companies will collaborate with supply chain partners and synchronise operations, (II) technology and the world wide web will be key enablers of innovative supply chain strategy, and (III) supply chain organisations will be restructured and re-skilled to achieve the benefits of synchronisation.

Holweg et al. (2005) addressed Anderson and Lee's first issue, by focusing on the characterisation of the operational dimensions of SSC. They define the SSC as "a supply chain sharing both demand visibility and decision-making responsibility with suppliers [...] that implies complete inventory and planning collaboration". In a SSC, the supplier takes charge of the customer's inventory replenishment on the operational level and uses this visibility in planning his/her own supply operations. Holweg et al. (2005) analyse several empirical cases of SSC implementations and illustrate the benefit of this configuration of supply chains. In particular, they argue that SSCs allow the elimination of bullwhip effect. Furthermore, linking the inventory and replenishment decision provides a reduction of inventory levels, a better utilisation of transportation resources, a better control of the risk for constrained materials, and a reduction of the rationing game by structured contracts.

Although synchronisation is recognised as an emerging issue in supply chain, the majority of the studies presented in literature merely report definitions and describe the benefits of SSC. According to Gunasekaran and Ngai (2009), more research is required on modelling and analysing coordination-level issues. Lyu et al. (2010) state that only few papers address how to build a collaborative replenishment mechanism model, or how to coordinate the replenishment mechanism between the supplier and the store-level retailer. Yu et al. (2010) assert that only few studies focus on how the different combinations of information sharing may affect the SSC performance.

Furthermore, several case studies show that some highly advocated large-scale collaboration projects, such as Vendor Managed Inventory (VMI), can degenerate into a five-to-one increase in the bullwhip effect at each level of the supply chain (Holweg et al., 2005). It is likely to consider that these failures are due to the fact that buyers and sellers, despite achieving information transparency, do not completely exploit the potential strength of full visibility (Fu and Zhu, 2010). On the contrary, due to a lack of understanding about how to create a joint decision making process for aligning individual plans, supply chain members continue to adopt order policies based on the same information as in a traditional supply chain, thus deriving no dynamic benefit (Holweg et al., 2005). As a consequence, several companies did not succeed in eliminating inefficiencies such as demand amplification (Disney et al., 2007). According to Lee (2010), taming the bullwhip requires collaboration, and consequently understanding that there is a need to clearly formalise how the replenishment policies in practical application should be modified in order to benefit from information sharing.

\subsection{Analysing a Synchronised Supply Chain: the components of production inventory control}

Our second research question is motivated by the need of quantifying the effectiveness of supply chain synchronisation against variations in the business context. In the real business world, environmental conditions often determine variations in processes, with regard to production and delivery lead time, and variations in the 
Table 1

Lead time, forecast factor and proportional controller in the Bullwhip Avoidance Phase.

\begin{tabular}{|c|c|c|c|c|c|c|}
\hline & Methodology & $\begin{array}{l}\text { Order } \\
\text { policy }\end{array}$ & Performance metrics & Supply chain structure & Focus of the analysis & \\
\hline $\begin{array}{l}\text { Chen et al. } \\
\text { (2000) }\end{array}$ & $\begin{array}{l}\text { Statistical } \\
\text { Methods }\end{array}$ & $(S, R)$ & $\begin{array}{l}\text { Order Rate Variance } \\
\text { Ratio }\end{array}$ & $\begin{array}{l}\text { Two Supply Chains } \\
\text { - Two-echelon } \\
\text { Traditional } \\
\text { - Multi-echelon Elec- } \\
\text { tronic Point Of Sales }\end{array}$ & $\begin{array}{l}\text { Relation between bullwhip, demand forecasting } \\
\text { and information sharing. Order Rate Variance Ratio } \\
\text { Metric }\end{array}$ & $\begin{array}{l}\text { Forecasting } \\
\text { factor }\end{array}$ \\
\hline $\begin{array}{l}\text { Dejonckheere } \\
\text { et al. (2002) }\end{array}$ & Discrete Time & Smoothing & $\begin{array}{l}\text { Amplitude Ratio Cost } \\
\text { Ratio }\end{array}$ & $\begin{array}{l}\text { Traditional Production- } \\
\text { Inventory System }\end{array}$ & $\begin{array}{l}\text { Relation between reducing exponential smoothing } \\
\text { forecast constant and bullwhip avoidance }\end{array}$ & \\
\hline $\begin{array}{l}\text { Dejonckheere } \\
\text { et al. (2003) }\end{array}$ & $\begin{array}{l}\text { Discrete Time } \\
\text { Optimisation } \\
\text { Methods }\end{array}$ & $\begin{array}{l}(S, R) \\
\text { Smoothing }\end{array}$ & $\begin{array}{l}\text { Order Rate Variance } \\
\text { Ratio }\end{array}$ & $\begin{array}{l}\text { Traditional Production- } \\
\text { Inventory System }\end{array}$ & $\begin{array}{l}\text { Different forecasting methods integrated into the } \\
\text { order-up-to system. }\end{array}$ & \\
\hline Zhang (2004) & $\begin{array}{l}\text { Optimisation } \\
\text { Method }\end{array}$ & $(S, R)$ & $\begin{array}{l}\text { Order Rate Variance } \\
\text { Ratio }\end{array}$ & $\begin{array}{l}\text { Traditional Production- } \\
\text { Inventory System }\end{array}$ & $\begin{array}{l}\text { Impact of the three different forecasting methods } \\
\text { on bullwhip effect. Relationship between demand } \\
\text { amplification and lead time reduction }\end{array}$ & \\
\hline $\begin{array}{l}\text { Chandra and } \\
\text { Grabis } \\
\text { (2005) }\end{array}$ & $\begin{array}{l}\text { Spreadsheet } \\
\text { Simulation }\end{array}$ & $(S, R)$ & $\begin{array}{l}\text { Order Rate Variance } \\
\text { Ratio Inventory }\end{array}$ & $\begin{array}{l}\text { Two-echelon } \\
\text { Traditional Supply } \\
\text { Chain }\end{array}$ & $\begin{array}{l}\text { Comparison of forecasting methods for the order- } \\
\text { up-to and MRP based approach. Benefit of } \\
\text { autoregressive models and multiple step forecasts } \\
\text { in case of serially correlated demand }\end{array}$ & \\
\hline $\begin{array}{l}\text { Ingalls et al. } \\
\qquad(2005)\end{array}$ & $\begin{array}{l}\text { Spreadsheet } \\
\text { Simulation } \\
\text { Statistical } \\
\text { Methods }\end{array}$ & $(S, R)$ & $\begin{array}{l}\text { Order Rate Variance } \\
\text { Ratio Backlog } \\
\text { Inventory }\end{array}$ & $\begin{array}{l}\text { Two-echelon } \\
\text { Traditional Supply } \\
\text { Chain }\end{array}$ & $\begin{array}{l}\text { Control-based forecasting techniques to dampen } \\
\text { amplification phenomenon }\end{array}$ & \\
\hline $\begin{array}{l}\text { Disney et al. } \\
\text { (2006) }\end{array}$ & Discrete Time & $\begin{array}{l}(S, R) \\
\text { Smoothing }\end{array}$ & $\begin{array}{l}\text { Order Rate Variance } \\
\text { Ratio Inventory } \\
\text { Variance Ratio Fill } \\
\text { Rate }\end{array}$ & $\begin{array}{l}\text { Traditional Production- } \\
\text { Inventory System }\end{array}$ & $\begin{array}{l}\text { Amplification variance and inventory variance as } \\
\text { function of smoothing and demand forecasting } \\
\text { parameters. Insight on customer service level }\end{array}$ & \\
\hline $\begin{array}{r}\text { Kim et al. } \\
(2006)\end{array}$ & $\begin{array}{l}\text { Statistical } \\
\text { Methods }\end{array}$ & $(S, R)$ & $\begin{array}{l}\text { Order Rate Variance } \\
\text { Ratio }\end{array}$ & $\begin{array}{l}\text { Two five-layer Supply } \\
\text { Chains } \\
\text { - Traditional } \\
\text { - Electronic Point of } \\
\text { Sales }\end{array}$ & $\begin{array}{l}\text { Bullwhip quantification under stochastic lead time, } \\
\text { different forecast methods and customer demand } \\
\text { information sharing }\end{array}$ & \\
\hline $\begin{array}{l}\text { Aggelogiannaki } \\
\text { et al. (2008) }\end{array}$ & $\begin{array}{l}\text { Discrete Time } \\
\text { Optimisation } \\
\text { Methods }\end{array}$ & Smoothing & $\begin{array}{l}\text { Order Rate Variance } \\
\text { Ratio Inventory } \\
\text { integrated squared } \\
\text { error }\end{array}$ & $\begin{array}{l}\text { Traditional Production- } \\
\text { Inventory System }\end{array}$ & $\begin{array}{l}\text { Benefit of adaptation capabilities in an inventory } \\
\text { control system. Effect of parameters variation on } \\
\text { demand amplification }\end{array}$ & \\
\hline $\begin{array}{l}\text { Kelepouris et al. } \\
\qquad(2008)\end{array}$ & $\begin{array}{l}\text { Spreadsheet } \\
\text { Simulation }\end{array}$ & $(S, R)$ & $\begin{array}{l}\text { Order Rate Variance } \\
\text { Ratio Fill Rate }\end{array}$ & $\begin{array}{l}\text { Two two-echelon } \\
\text { Supply Chains } \\
\text { - Traditional } \\
\text { - Electronic Point of } \\
\text { Sales }\end{array}$ & $\begin{array}{l}\text { Impact of lead time, exponential smoothing forecast } \\
\text { factor and safety stock on bullwhip effect }\end{array}$ & \\
\hline $\begin{array}{l}\text { Wright and } \\
\text { Yuan (2008) }\end{array}$ & $\begin{array}{l}\text { Continuous } \\
\text { Time }\end{array}$ & Smoothing & $\begin{array}{l}\text { Order Rate Variance } \\
\text { Ratio Root Mean } \\
\text { Square Costs }\end{array}$ & $\begin{array}{l}\text { Four-echelon } \\
\text { Traditional Supply } \\
\text { Chain }\end{array}$ & $\begin{array}{l}\text { Impact of forecasting method and adjustment of } \\
\text { stock levels and work in progress on supply chain } \\
\text { stability }\end{array}$ & \\
\hline $\begin{array}{l}\text { Wang et al. } \\
\qquad(2010)\end{array}$ & $\begin{array}{l}\text { Spreadsheet } \\
\text { Simulation }\end{array}$ & $(S, R)$ & $\begin{array}{l}\text { Costs Order Rate } \\
\text { Variance Ratio }\end{array}$ & $\begin{array}{l}\text { Traditional Production- } \\
\text { Inventory System }\end{array}$ & $\begin{array}{l}\text { Influence of forecast-updating methods in the } \\
\text { amplification of bullwhip effect }\end{array}$ & \\
\hline & & & & $\begin{array}{l}\text { Two multi-echelon } \\
\text { Supply Chains }\end{array}$ & & Lead time \\
\hline $\begin{array}{l}\text { Cachon and } \\
\text { Fisher } \\
(2000)\end{array}$ & $\begin{array}{l}\text { Optimisation } \\
\text { Methods }\end{array}$ & $(S, R)$ & Costs & $\begin{array}{l}\text { - Traditional } \\
\text { - Vendor Managed } \\
\quad \text { Inventory } \\
\text { Two four-echelon } \\
\text { Supply Chains }\end{array}$ & $\begin{array}{l}\text { Impact of information sharing on batch size and } \\
\text { lead time reduction }\end{array}$ & \\
\hline $\begin{array}{l}\text { Chatfield et al. } \\
\text { (2004) }\end{array}$ & $\begin{array}{l}\text { Object- } \\
\text { Oriented } \\
\text { Simulation }\end{array}$ & $(S, R)$ & $\begin{array}{l}\text { Order Rate Variance } \\
\text { Ratio }\end{array}$ & $\begin{array}{l}\text { - Traditional } \\
\text { - Electronic Point Of } \\
\quad \text { Sales } \\
\text { Two five-layer Supply } \\
\text { Chains }\end{array}$ & $\begin{array}{l}\text { Relation between bullwhip effect and lead time } \\
\text { variation, customer demand sharing information } \\
\text { and data used to forecast lead time }\end{array}$ & \\
\hline $\begin{array}{r}\text { Kim et al. } \\
(2006)\end{array}$ & $\begin{array}{l}\text { Statistical } \\
\text { Methods }\end{array}$ & $(S, R)$ & $\begin{array}{l}\text { Order Rate Variance } \\
\text { Ratio }\end{array}$ & $\begin{array}{l}\text { - Traditional } \\
\text { - Electronic Point of } \\
\quad \text { Sales }\end{array}$ & $\begin{array}{l}\text { Bullwhip quantification under stochastic lead time, } \\
\text { different forecast methods and customer demand } \\
\text { information sharing }\end{array}$ & \\
\hline $\begin{array}{l}\text { Boute et al. } \\
\text { (2007) }\end{array}$ & Discrete Time & Smoothing & Fill Rate & $\begin{array}{l}\text { Two-echelon } \\
\text { Traditional Supply } \\
\text { Chain }\end{array}$ & $\begin{array}{l}\text { Benefit on inventory cost provided by a shorter and } \\
\text { less variable lead time through smoothing } \\
\text { production order pattern }\end{array}$ & \\
\hline $\begin{array}{l}\text { Jakšič and } \\
\text { Rusjan } \\
\text { (2008) }\end{array}$ & Discrete Time & Smoothing & $\begin{array}{l}\text { Order Rate Variance } \\
\text { Ratio }\end{array}$ & $\begin{array}{l}\text { Two-echelon } \\
\text { Traditional Supply } \\
\text { Chain }\end{array}$ & $\begin{array}{l}\text { Impact of different replenishment policies on } \\
\text { demand amplification }\end{array}$ & \\
\hline $\begin{array}{l}\text { Kim and } \\
\text { Springer } \\
(2008)\end{array}$ & $\begin{array}{l}\text { Continuous } \\
\text { Time }\end{array}$ & Smoothing & Amplification ratio & $\begin{array}{l}\text { Two-echelon } \\
\text { Traditional Supply } \\
\text { Chain } \\
\text { Two two-echelon } \\
\text { Supply Chains }\end{array}$ & $\begin{array}{l}\text { Relation between lead times and cyclical oscillation } \\
\text { of inventory. Insight on smoothing replenishment } \\
\text { parameters }\end{array}$ & \\
\hline $\begin{array}{l}\text { Kelepouris et al. } \\
\qquad(2008)\end{array}$ & $\begin{array}{l}\text { Spreadsheet } \\
\text { Simulation }\end{array}$ & $(S, R)$ & $\begin{array}{l}\text { Order Rate Variance } \\
\text { Ratio Fill Rate }\end{array}$ & $\begin{array}{l}\text { - Traditional } \\
\text { - Electronic Point Of } \\
\quad \text { Sales }\end{array}$ & $\begin{array}{l}\text { Impact of lead time, exponential smoothing forecast } \\
\text { factor and safety stock on bullwhip effect }\end{array}$ & \\
\hline
\end{tabular}


Table 1 (continued)

\begin{tabular}{|c|c|c|c|c|c|c|}
\hline & Methodology & $\begin{array}{l}\text { Order } \\
\text { policy }\end{array}$ & Performance metrics & Supply chain structure & Focus of the analysis & \\
\hline $\begin{array}{l}\text { Chaharsooghi } \\
\text { and Heydari } \\
\text { (2010) }\end{array}$ & $\begin{array}{l}\text { Simulation } \\
\text { Statistical } \\
\text { Methods }\end{array}$ & $(S, R)$ & $\begin{array}{l}\text { Order Rate Variance } \\
\text { Ratio Inventory Stock } \\
\text { Out size Stock Out } \\
\text { number }\end{array}$ & $\begin{array}{l}\text { Four-echelon Electronic } \\
\text { Point Of Sales Supply } \\
\text { Chain }\end{array}$ & $\begin{array}{l}\text { Relative importance of lead time variance and lead } \\
\text { time mean value on supply chain performance }\end{array}$ & \\
\hline $\begin{array}{l}\text { Disney et al. } \\
\text { (2004b) }\end{array}$ & $\begin{array}{l}\text { Discrete Time } \\
\text { Optimisation } \\
\text { Methods }\end{array}$ & Smoothing & $\begin{array}{l}\text { Order Rate Variance } \\
\text { Ratio Inventory } \\
\text { Variance Ratio }\end{array}$ & $\begin{array}{l}\text { Traditional Production- } \\
\text { Inventory System }\end{array}$ & $\begin{array}{l}\text { Analytical relationship between smoothing } \\
\text { parameters and demand amplification. The } \\
\text { bullwhip Golden Ratio }\end{array}$ & $\begin{array}{l}\text { Smoothing } \\
\text { parameters }\end{array}$ \\
\hline $\begin{array}{l}\text { Disney et al. } \\
\text { (2006) }\end{array}$ & Discrete Time & $\begin{array}{l}(S, R) \\
\text { Smoothing }\end{array}$ & $\begin{array}{l}\text { Order Rate Variance } \\
\text { Ratio Inventory } \\
\text { Variance Ratio Fill } \\
\text { Rate }\end{array}$ & $\begin{array}{l}\text { Traditional Production- } \\
\text { Inventory System }\end{array}$ & $\begin{array}{l}\text { Amplification variance and inventory variance as } \\
\text { function of smoothing and demand forecasting } \\
\text { parameters. Insight on customer service level }\end{array}$ & \\
\hline $\begin{array}{l}\text { Kim and } \\
\text { Springer } \\
(2008)\end{array}$ & $\begin{array}{l}\text { Continuous } \\
\text { Time }\end{array}$ & Smoothing & Amplification ratio & $\begin{array}{l}\text { Two-echelon } \\
\text { Traditional Supply } \\
\text { Chain }\end{array}$ & $\begin{array}{l}\text { Relation between lead times and cyclical oscillation } \\
\text { of inventory. Insight on smoothing replenishment } \\
\text { parameters }\end{array}$ & \\
\hline $\begin{array}{l}\text { Aggelogiannaki } \\
\text { et al. (2008) }\end{array}$ & $\begin{array}{l}\text { Discrete Time } \\
\text { Optimisation } \\
\text { Methods }\end{array}$ & Smoothing & $\begin{array}{l}\text { Order Rate Variance } \\
\text { Ratio Inventory } \\
\text { integrated squared } \\
\text { error }\end{array}$ & $\begin{array}{l}\text { Traditional Production- } \\
\text { Inventory System }\end{array}$ & $\begin{array}{l}\text { Benefit of adaptation capabilities in an inventory } \\
\text { control system. Effect of parameters variation on } \\
\text { demand amplification }\end{array}$ & \\
\hline $\begin{array}{l}\text { Caloiero et al. } \\
\qquad(2008)\end{array}$ & Discrete Time & Smoothing & $\begin{array}{l}\text { Costs Order Rate } \\
\text { Variance Ratio }\end{array}$ & $\begin{array}{l}\text { Traditional Production- } \\
\text { Inventory System }\end{array}$ & $\begin{array}{l}\text { Relation between bullwhip and replenishment } \\
\text { parameters }\end{array}$ & \\
\hline $\begin{array}{l}\text { Chen and Lee } \\
\text { (2009) }\end{array}$ & $\begin{array}{l}\text { Statistical } \\
\text { Methods }\end{array}$ & Smoothing & $\begin{array}{l}\text { Costs Order Rate } \\
\text { Variance Ratio }\end{array}$ & $\begin{array}{l}\text { Two-echelon Supply } \\
\text { Chain in which the } \\
\text { retailer shares } \\
\text { projected future orders }\end{array}$ & $\begin{array}{l}\text { Optimal order-smoothing weight to minimise total } \\
\text { costs under a general demand model }\end{array}$ & \\
\hline
\end{tabular}

parameters of the decision policies (e.g. proportional controllers of the order policy and demand forecasting parameter).

Lead time is recognised in literature as one of the variables that mostly impact on the effectiveness of operations in the supply chain (Wikner et al., 1991; Towill, 1996; Chen et al., 2000; Disney and Towill, 2003; Chatfield et al., 2004; Zhang, 2004; Chandra and Grabis, 2005; Disney et al., 2006; Kim et al., 2006; Kelepouris et al., 2008; Agrawal et al., 2009), and it was identified by Lee et al. (1997) as one of the main causes of bullwhip effect. Lead time reduction was recognised as a direct driver for business improvement (Time Compression Paradigm, see Towill, 1996).

Different forecasting methods have been employed in modelling studies during the Bullwhip Avoidance Phase (Chen et al., 2000; Dejonckheere et al., 2002; Dejonckheere et al., 2003; Zhang, 2004; Chandra and Grabis, 2005; Ingalls et al., 2005; Disney et al., 2006; Kim et al., 2006; Kelepouris et al., 2008; Wright and Yuan, 2008). Motivated by the work of Disney and Lambrecht (2008), we select exponential smoothing as demand forecasting method. As reported by the authors, simple exponential smoothing is a good choice for one-period-ahead forecasting and it resulted to be the preferred technique among several methods in the over-cited article by Makridakis et al. (1982).

The proportional controller of the replenishment rule can be considered one of the major topics in the Bullwhip Avoidance Phase. The proportional controller of a periodic review orderup-to is a smoothing term of the discrepancy between current and target levels of net stock (or inventory) and pipeline stock (or work in progress). For an extensive discussion on smoothing replenishment rules see Lalwani et al. (2006) and Sarimveis et al. (2008). It has been shown in the literature that properly tuning the value of the smoothing parameters of a $(S, R)$ policy offers an opportunity to reduce bullwhip (Disney and Towill, 2003). Several studies show that order rate stability tends to improve for proper tuning of the proportional controllers (Disney and Towill, 2003; Disney et al., 2004a; Boute et al., 2007; Chen and Disney, 2007; Disney et al., 2007; Warburton and Disney, 2007; Bayraktar et al., 2008; Cannella and Ciancimino, 2010). Table 1 reports an overview of relevant supply chain contributions published during the Bullwhip Avoidance Phase.
To quantify the SSC response to variations of the operational parameters we perform a supply chain stress test on the SSC. More specifically, following Towill et al.'s (2007) stress test perspective, we study different parameter settings of the supply chain under a sudden and intense change in demand. The following variables of production inventory control are subject to variation within the experimental setting: lead time, demand forecast factor and proportional controllers of the replenishment rule. We model the supply chain configurations through first-order non-linear difference equations (Riddalls et al., 2000; Ciancimino and Cannella, 2011). We adopt the single-product modelling assumption, widely used in bullwhip analysis (see e.g. Dejonckheere et al. (2003), Disney and Towill (2003), Chandra and Grabis (2005), Gonçalves et al. (2005), Boute et al. (2007), Hosoda and Disney (2006), Ouyang (2007), Agrawal et al. (2009), Springer and Kim (2010)).

\section{Model development: inventory control policy and information flows in the $(S, R)$ Synchronised Supply Chain}

This section is devoted to present the conceptual model and the mathematical formulae regulating orders and material flow in a SSC. In the first Section 3.1 we formalise how supply chain members in a SSC align their production-inventory systems. To fulfil the first research objective, we derive the $(S, R)$ order quantity for a SSC and define explicitly the information to be shared for inventory and planning collaboration. In the second Section 3.2 the SSC model is presented. The $(S, R)$ smoothing replenishment rule is used to model a SSC through a non-linear first-order difference equations system. Assumptions, information and material flows are detailed.

Table 2 reports the model notation.

\section{1. $(S, R)$ Order quantity for the Synchronised Supply Chain}

As a starting point, the $(S, R)$ order quantity for a generic echelon is first derived in a classical traditional supply chain. The same procedure is then applied to derive the order quantity for a SSC.

We focus on the periodic review rule known as $(S, R)$ orderup-to. In practical applications the $(S, R)$ is the most largely used policy (Hax and Candea, 1984), given the common practice in 
Table 2

Notation.

\begin{tabular}{|c|c|c|c|}
\hline \multicolumn{4}{|c|}{ Model variables and parameters } \\
\hline$R$ & Review period & $d$ & Customer demand \\
\hline$S$ & Order-up-to level in the traditional supply chain & $\hat{d}$ & Customer demand forecast \\
\hline$S^{\prime}$ & Order-up-to level in the SSC & $\alpha$ & Demand smoothing forecasting factor \\
\hline 0 & Replenishment order quantity in the traditional supply chain & $\lambda$ & Production-distribution lead time \\
\hline$\widehat{O}$ & Forecast on the order quantity incoming from subsequent echelon & $\varepsilon$ & Safety stock factor \\
\hline$O^{\prime}$ & Replenishment order quantity in the SSC & $\lambda^{\prime}$ & Multi-echelon production-distribution lead time \\
\hline$W$ & Work in progress & $\varepsilon^{\prime}$ & Multi-echelon safety stock factor \\
\hline$I$ & On-hand inventory of finished materials & $\beta$ & Proportional controller \\
\hline$B$ & Backlog of orders & $p$ & Generic echelon's position in the serial system \\
\hline C & Units/orders finally delivered & $W^{\prime}$ & Multi-echelon work in progress \\
\hline$I^{\prime}$ & Multi-echelon inventory & & \\
\hline \multicolumn{4}{|c|}{ Statistics } \\
\hline$\sigma_{d}^{2}$ & Variance of the market demand & $\mu_{d}$ & Steady state market demand \\
\hline$\sigma_{0}^{2}$ & Variance of the order quantity & $\mu_{I}$ & Steady state value of the inventory level \\
\hline$\sigma_{I}^{2}$ & Variance of the inventory & $\vartheta_{P C B}$ & Proportional controller bullwhip angle \\
\hline$\mu_{O}$ & Steady state value of the order rate & $\vartheta_{P C I I}$ & Proportional controller inventory instability angle \\
\hline \multicolumn{4}{|c|}{ Time variables } \\
\hline$T$ & Time horizon & $\tau^{\prime \prime}$ & Finishing time of Fill Rate $<1$ (stock-out) \\
\hline$\Gamma$ & Limited time interval & $\tilde{\tau}^{\prime}$ & Starting time of Fill Rate $<1$ in the worst case \\
\hline$\tau^{\prime}$ & Starting time of Fill Rate $<1$ (stock-out) & $\tilde{\tau}^{\prime \prime}$ & Finish time of Fill Rate $<1$ in the worst case \\
\hline \multicolumn{4}{|c|}{ Indices } \\
\hline$i$ & Echelon in the serial system & $\omega$ & Generic experimental set \\
\hline K & Total number of echelons & & \\
\hline
\end{tabular}

retailing to replenish inventories frequently and the tendency of manufacturers to produce to demand (Disney and Lambrecht, 2008).

In the $(S, R)$ rule, a quantity $O$ is ordered to bring the level of the available inventory up to a level $S$ at each review time $R$. In the following mathematical formulae (Eqs. (1)-(12)) $S$ is dynamically computed at each review period $R$, and every variable is meant to refer to the period $t$ before the mathematical derivation of the $(S, R)$ order-up-to order quantity. According to the $(S, R)$ rule, the order-up-to order quantity for a generic echelon $i$ used in period $t$ is given by Eq. (1).

\section{$\mathrm{O}=\mathrm{S}-$ inventory position}

In a traditional production-distribution system, orders incoming from the adjacent successor are the only external information a generic echelon has access to. The $S$ level for a generic echelon $i$ (Eq. (2)) is equal to the forecast of the orders $O_{i+1}$ coming from the subsequent echelon $i+1$ during the review period $R\left(R_{i} \widehat{O}_{i+1}\right)$, plus the forecast of the order from echelon $i+1$ during the production-delivery lead time $\lambda\left(\lambda_{i} \widehat{O}_{i+1}\right)$, plus a safety stock to prevent shortages $\left(\varepsilon_{i} \widehat{O}_{i+1}\right)$. The safety stock depends on a factor $\varepsilon$ and it is expected to provide sufficient stock to prevent a possible stockout during the lead time $\lambda$ plus the review period $R$ (Disney and Lambrecht, 2008). Thus:

$S_{i}(t)=R_{i} \widehat{O}_{i+1}(t)+\lambda_{i} \widehat{O}_{i+1}(t)+\varepsilon_{i} \widehat{O}_{i+1}(t)$

The inventory position is given by the inventory on hand $I$ plus the pipeline inventory or work in progress $W(W I P)$. In the present notation, WIP is the sum of the products already shipped by not received by the customer yet. The order quantity for echelon $i$ is herein derived for $R=1$ (3) and Eq. (4). The review period is a further decision variable but in order to simplify the analysis and without lose of generality we set $R$ equal to one base period as, e.g., in Disney et al. (2007)

$O_{i}(t)=\widehat{O}_{i+1}(t)+\lambda_{i} \widehat{O}_{i+1}(t)+\varepsilon_{i} \widehat{O}_{i+1}(t)-I_{i}(t)-W_{i}(t)$

$O_{i}(t)=\widehat{O}_{i+1}(t)+\left(\varepsilon_{i} \widehat{O}_{i+1}(t)-I_{i}(t)\right)+\left(\lambda_{i} \widehat{O}_{i+1}(t)-W_{i}(t)\right)$

According to Disney and Lambrecht (2008), the term $\varepsilon_{i} \widehat{O}_{i+1}$ can be viewed as a target net stock. The target net stock is updated every period according to the new forecast on the incoming orders and it is equivalent to a safety stock (Dejonckheere et al., 2004; Disney et al., 2006). Analogously, the term $\lambda_{i} \widehat{O}_{i+1}$ represents a target pipeline stock or target work in progress.

To extend the previous mathematical formulation for the generation of the order quantity in a SSC, we first underline the perspective shift of SSC. The aim of a generic tier is not to satisfy the order generated by the subsequent adjacent stage, but the demand coming from the market. In the SSC, each echelon has access to the final customer demand and it regulates its inventory and production system to satisfy it. This implies that, at every stage, the risk period (lead time plus review period) has to be referred to the entire time length needed to deliver the finished product from the generic tier to the final customer. To estimate the risk period in a SSC, a generic echelon needs to access downstream partners' operational information, such as lead times.

We denote by $S^{\prime}$ the order-up-to level for the SSC. The $S^{\prime}$ level for a generic echelon $i$ (Eq. (5)) is equal to the forecast of customer demand $d$ during the review period $R\left(R_{i} \hat{d}\right)$, plus the expected customer demand during the multi-echelon lead time $\lambda^{\prime}\left(\lambda_{i}^{\prime} \hat{d}\right)$, plus the multi-echelon safety stock to prevent shortages $\left(\varepsilon_{i}^{\prime} \hat{d}\right)$.

$S_{i}^{\prime}(t)=R_{i} \hat{d}(t)+\lambda_{i}^{\prime} \hat{d}(t)+\varepsilon_{i}^{\prime} \hat{d}(t)$

The multi-echelon lead time $\lambda^{\prime}$ for echelon $i$ represents the entire time period needed to deliver the finished product from the generic tier $i$ to the final customer $K+1$ (Eq. (6)).

$\lambda_{i}^{\prime}=\sum_{j=i}^{K} \lambda_{j}$

Analogously, the multi-echelon safety stock factor from echelon $i$ to customer $K+1$ is given by Eq. (7).

$\varepsilon_{i}^{\prime}=\sum_{j=i}^{K} \varepsilon_{j}$

The inventory position for the SSC order-up-to at echelon $i$ is given by the multi-echelon inventory $I^{\prime}$ (Eq. (8)) (inventory on hand in echelon $i$ plus inventories of subsequent echelons) plus multiechelon pipeline inventory or multi-echelon work in progress $W^{\prime}$ 
(Eq. (9)) (pipeline inventory in echelon $i$ plus pipeline inventories of subsequent echelons).

$$
\begin{aligned}
& I_{i}^{\prime}(t)=\sum_{j=i}^{K} I_{j}(t) \\
& W_{i}^{\prime}(t)=\sum_{j=i}^{K} W_{j}(t)
\end{aligned}
$$

The order quantity $O^{\prime}$ is derived for $R=1 \forall i$ (Eqs. (10) and (11)).

$$
\begin{aligned}
& O_{i}^{\prime}(t)=\lambda_{i}^{\prime} \hat{d}(t)+\hat{d}(t)+\varepsilon_{i}^{\prime} \hat{d}(t)-I_{i}^{\prime}(t)-W_{i}^{\prime}(t) \\
& O_{i}^{\prime}(t)=\hat{d}+\left(\varepsilon_{i}^{\prime} \hat{d}(t)-I_{i}^{\prime}(t)\right)+\left(\lambda_{i}^{\prime} \hat{d}(t)-W_{i}^{\prime}(t)\right)
\end{aligned}
$$

The term $\varepsilon_{i}^{\prime} \hat{d}$ can be viewed as a multi-echelon target net stock and the term $\lambda_{i}^{\prime} \hat{d}$ as a multi-echelon target pipeline stock or multiechelon target work in progress.

Eq. (11) formalises the demand visibility, inventory visibility and planning collaboration principles of a $(S, R)$ SSC. This ordering rule can be modified into a widely used smoothing replenishment rule, by adopting proportional controllers (Eq. (12))

$O_{i}^{\prime}(t)=\hat{d}(t)+\beta_{i}\left(\varepsilon_{i}^{\prime} \hat{d}(t)-I_{i}^{\prime}(t)+\lambda_{i}^{\prime} \hat{d}(t)-W_{i}^{\prime}(t)\right)$

Fig. 1 summarises the exchange of information and material flows discussed above.

\subsection{The Synchronised Supply Chain difference equations model}

The smoothing replenishment rule derived in the previous subsection (Eq. (12)) is used to model a SSC via a non-linear first-order difference equation system. The mathematical formalism of the SSC model is reported below. Echelon $i=1$ stands for the manufacturer and $i=K+1$ for the final customer. Fig. 2 shows the material flow in SSC.
The SSC is modelled under the following assumptions: (a) $\mathrm{K}$ stage production-distribution serial system. Each echelon in the system has a single successor and a single predecessor; (b) Unconstrained production-distribution capacity. No quantity limitations in production, buffering and transport are considered; (c) Single product. Aggregate production plans are assumed; (d) Non-negative condition of order quantity. Products delivered cannot be returned to the supplier; (e) Backlog allowed as a consequence of stock out. Orders not fulfilled in time are backlogged and the back$\log$ is fulfilled as soon as on-hand inventory becomes available; ( $f$ ) Unlimited raw material supply. Orders from echelon $i=1$ (producer) are always entirely fulfilled on time; (g) Market demand is visible to all echelons. All echelons adopt the exponential smoothing rule to forecast demand; h) A generic echelon $i$ receives information about order quantity $\mathrm{O}_{i+1}^{\prime}$ from the downstream adjacent echelon $i+1$, on the up-to-date market demand $d$ and on safety stock factors $\varepsilon_{j}$, lead times $\lambda_{j}$, inventory levels $I_{j}$, and work in progress levels $W_{j}$ from all downstream echelons $j=i+1, \ldots, K$.

The mathematical formulation of the SSC model is reported in the following.

Eqs. (13)-(15) define the state variables of the model (work in progress, inventory and backlog). The relation regulating the work in progress variable is such that, for each echelon $i$, the products sent from supplier $C_{i-1}$ immediately become work in progress (Eq. (13)).

$W_{i}(t)=W_{i}(t-1)+C_{i-1}(t)-C_{i-1}\left(t-\lambda_{i}\right)$

The inventory is decreased by the quantity $C_{i}$ (items sent to the downstream echelon) and increased by the quantity $C_{i-1}$ sent by the supplier at time $\left(t-\lambda_{i}\right)$ (Eq. (14)).

$I_{i}(t)=I_{i}(t-1)+C_{i-1}\left(t-\lambda_{i}\right)-C_{i}(t)$

Eq. (15) describes the backlog $\left(B_{i}(t)\right)$ as the sum of unfulfilled orders (orders from the subsequent echelon minus delivered items).

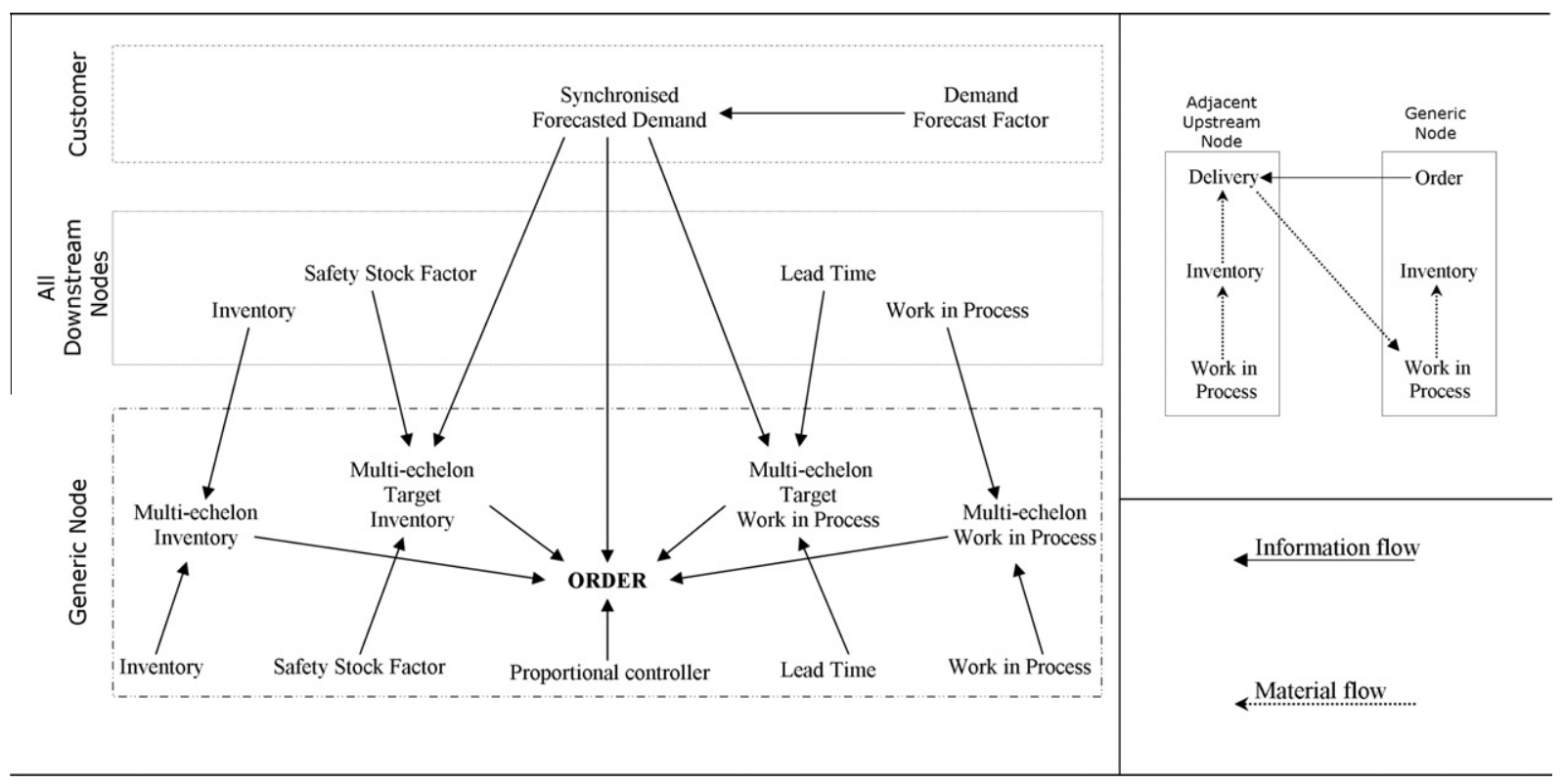

Fig. 1. SSC orders and material flow regulation.

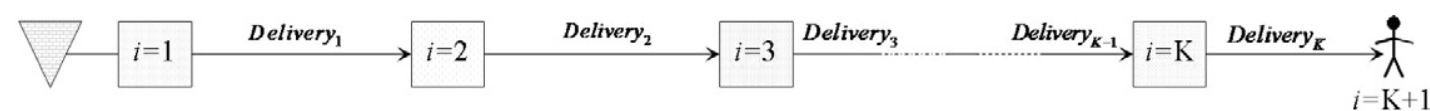

Fig. 2. Serial supply chain material flow. 
Table 3

SSC equations.

\begin{tabular}{|c|c|c|}
\hline Work in progress & $W_{i}(t)=W_{i}(t-1)+C_{i-1}(t)-C_{i-1}\left(t-\lambda_{i}\right)$ & (13) \\
\hline Inventory & $I_{i}(t)=I_{i}(t-1)+C_{i-1}\left(t-\lambda_{i}\right)-C_{i}(t)$ & (14) \\
\hline Backlog & $B_{i}(t)=B_{i}(t-1)+O_{i+1}^{\prime}(t)-C_{i}(t)$ & (15) \\
\hline Orders finally delivered & $C_{i}(t)=\min \left\{O_{i+1}^{\prime}(t)+B_{i}(t-1) ; I_{i}(t-1)+C_{i-1}\left(t-\lambda_{i}\right)\right\}$ & (16) \\
\hline Demand forecast & $\hat{d}(t)=\alpha d(t-1)+(1-\alpha) \hat{d}(t-1)$ & $(17)$ \\
\hline Non-negativity condition of order quantity & $O_{i}(t) \geqslant 0$ & (18) \\
\hline Infinite raw material availability for the manufacturer & $C_{i-1}(t)=O_{1}^{\prime}(t) ; i=1$ & (19) \\
\hline Multi-echelon lead time & $\lambda_{i}^{\prime}=\sum_{j=i}^{K} \lambda_{j}$ & (6) \\
\hline Multi-echelon safety stock factor & $\varepsilon_{i}^{\prime}=\sum_{j=i}^{K} \varepsilon_{j}$ & (7) \\
\hline Multi-echelon Inventory & $I_{i}^{\prime}(t)=\sum_{j=i}^{K} I_{j}(t)$ & (8) \\
\hline Target Multi-echelon Inventory & $W_{i}^{\prime}(t)=\sum_{j=i}^{K} W_{j}(t)$ & (9) \\
\hline Order quantity & $O_{i}^{\prime}(t)=\hat{d}(t)+\beta_{i}\left(\varepsilon_{i}^{\prime} \hat{d}(t)-I_{i}^{\prime}(t)+\lambda_{i}^{\prime} \hat{d}(t)-W_{i}^{\prime}(t)\right)$ & $(12)$ \\
\hline
\end{tabular}

$B_{i}(t)=B_{i}(t-1)+O_{i+1}^{\prime}(t)-C_{i}(t)$

Eq. (16) defines the item delivery from one echelon to its successor

$C_{i}(t)=\min \left\{O_{i+1}^{\prime}(t)+B_{i}(t-1) ; I_{i}(t-1)+C_{i-1}\left(t-\lambda_{i}\right)\right\}$

Eq. (16) models the non-negativity condition of inventory, as is explained in the following: if $C_{i}(t)=O_{i+1}^{\prime}(t)+B_{i}(t-1)$, then the delivered quantity is exactly equal to what was ordered from the adjacent echelon plus the backlogged quantity, which is non-negative (see Eq. (18) below). Consequently, $I_{i}(t-1)+C_{i-1}\left(t-\lambda_{i}\right) \geqslant$ $O_{i+1}^{\prime}(t)+B_{i}(t-1) \geqslant 0$. If $C_{i}(t)=I_{i}(t-1)+C_{i-1}\left(t-\lambda_{i}\right)$, then the quantity that can be delivered is the total amount of items in the inventory at time $t$ (sum of inventory at time $t$ plus items sent by the precedent node one lead time before). Therefore, $I_{i}(t-1)=0$.

Eq. (17) models the exponential smoothing demand forecast rule, where the value of $\alpha$ reflects the weight given to the most recent observation $d(t-1)$

$\hat{d}(t)=\alpha d(t-1)+(1-\alpha) \hat{d}(t-1)$

Eq. (18) models assumption (d), the non-negativity condition of order quantity

$O_{i}^{\prime}(t) \geqslant 0$

In order to model the infinite raw material availability assumption, orders from echelon $i=1$ are always entirely fulfilled, as in Beamon and Chen (2001):

$C_{i-1}(t)=O_{1}^{\prime}(t) ; i=1$

The following section presents in detail the metric system used to support the analysis and to evaluate the performance of the SSC. The equations of the SSC model are summarised in Table 3.

\section{The performance measurement system}

Since partners in a SSC are collectively responsible for revenue growth, costs, asset utilisation and service levels, joint or extended measures are necessary to account for the integrated activities properly (Lee, 2000). In this work, in order to assess the SSC performance upon variations of lead time, demand smoothing forecasting factor and proportional controller of the replenishment rule, the model is evaluated under a variety of measures. The operational performance is measured via a set of metrics, whose reduction reflects improved cost effectiveness of members' operations. These metrics are employed to evaluate the performance of the SSC in terms of operational effectiveness both at a single echelon level (Order Rate Variance Ratio and Inventory Variance Ratio) and at a system level (Bullwhip Slope and Inventory Instability Slope). Customer service level is assessed by the widely adopted
Fill Rate measure, whose increase indicates a reduction of backlog and a decrease of stock-out costs.

\subsection{Order Rate Variance Ratio (ORVrR)}

This metric was proposed by Chen et al. (2000) and it is so far the most common bullwhip-related measure in the literature (Disney and Lambrecht, 2008). It compares the variance of the order rate $\sigma_{O}^{2}$ with the variance of market demand $\sigma_{d}^{2}$, both divided by their respective mean value $\mu$ (coefficient of variation). Therefore, Order Rate Variance Ratio is a quantification of the instability of orders in the network:

Order Rate Variance Ratio ${ }_{i}=\frac{\sigma_{O_{i}}^{2} / \mu_{O_{i}}}{\sigma_{d}^{2} / \mu_{d}}$

\subsection{Inventory Variance Ratio (IVrR)}

This metric was proposed by Disney and Towill (2003) to measure net stock instability, as it quantifies the fluctuations in actual inventory $\sigma_{I}^{2}$ against the fluctuation in demand $\sigma_{d}^{2}$. An increased inventory variance results in higher holding and backlog costs, and increasing average inventory costs per period (Disney and Lambrecht, 2008)

Inventory Variance Ratio $_{i}=\frac{\sigma_{I_{i}}^{2} / \mu_{I_{i}}}{\sigma_{d}^{2} / \mu_{d}}$

\subsection{Fill Rate}

Fill Rate is representative of customer service level (Zipkin, 2000), as it quantifies the percentage of items delivered to the final customer $C_{K}$ with respect to the actual market demand $d$. Fill Rate is computed every review time $R$ and its time series reproduce the history of the delivery system effectiveness

Fill Rate $(t)=\frac{C_{K}(t)}{d(t)}$

The Average Fill Rate (Eq. (23)) is the mean of a subset of Fill Rate values computed over a limited time interval $\Gamma \subseteq T$. The interval $\Gamma$ (Eq. (24)) is selected by considering, among all experimental sets $\omega$, the longest time $\operatorname{span}\left[\tilde{\tau}^{\prime \prime}-\tilde{\tau}^{\prime}\right]$ with Fill Rate values lower than 1, i.e., the maximum duration of shortage. The index $\omega$ represents the generic numerical experiment belonging to a "class" of comparison: in this work there is only one class, but when comparing different supply chain archetypes each structure $j$ generates a different subset $\omega_{j}$ (Cannella et al., 2010a). This procedure allows us to analyse the production-distribution network during stock-outs and to compare the magnitude of backlog among the different experimental sets (Ciancimino et al., 2009). The problem of quantifying the 
Table 4

Framework of the performance measurement system.

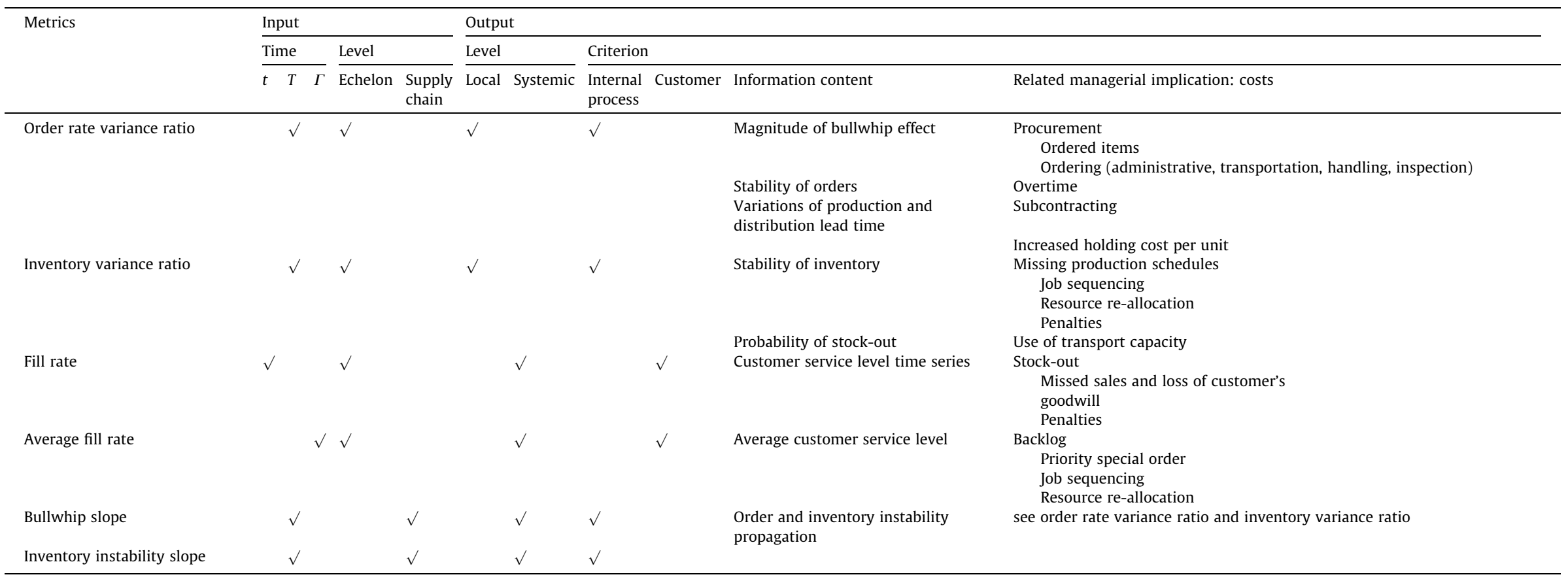


stock-out costs is a difficult and unsatisfactorily solved question in inventory theory, especially because of the intangible components (Hax and Candea, 1984). The adoption of a limited time interval $\Gamma$ to compute the customer service level is related to a widely employed assumption to estimate the stock-out cost as proportional to the product of the number of units out of stock and the duration of stock-out, such as in Holt et al. (1960).

$$
\begin{aligned}
& \text { Average Fill Rate }=\frac{1}{\Gamma} \sum_{t=\tilde{\tau}^{\prime}}^{\tilde{\tau}^{\prime \prime}} \text { Fill Rate }(t) \\
& \Gamma=\max _{\omega}\left(\tilde{\tau}^{\prime \prime}-\tilde{\tau}^{\prime}\right)=\tilde{\tau}^{\prime \prime}-\tilde{\tau}^{\prime}
\end{aligned}
$$

\subsection{Bullwhip Slope and Inventory Instability Slope}

Dejonckheere et al. (2004) presented a study on the dynamic behaviour of multi-echelon replenishment rules in a four-tier supply chain. They adopted the Order Rate Variance Ratio to assess different bullwhip solution approaches. In order to compare several supply chain configurations, they plotted the obtained values using the echelon position as independent variable. They observed the interpolated curve and inferred qualitatively on the linear or geometric nature of the trend. The authors state that a geometric increase of the Order Rate Variance Ratio interpolating curve is representative of strong bullwhip propagation, more intense than in a linear trend. Dejonckheere et al.'s curve is a smart representation of bullwhip propagation in a multi-echelon system and serves to concisely compare different supply chain configurations (Cannella et al., 2008; Ciancimino and Cannella, 2009). To extend Dejonckheere et al.'s inferring technique to a general case, a statistical analysis of the curve could be performed for both Order Rate Variance Ratio and Inventory Variance Ratio. We assume a linear propagation of bullwhip and inventory instability. This allows us to use slopes for the comparison of different boundary conditions generated by the different parameter settings. By defining $\vartheta_{O R V r R}$ as the angle of inclination of the linear regression of Order Rate Variance Ratio in Dejonckheere et al.'s curve, and $\vartheta_{I V r R}$ as the angle of inclination of the linear regression of Inventory Variance Ratio in Dejonckheere et al.'s curve, $p_{i}$ as the position of $i$ th echelon, Bullwhip Slope and Inventory Instability Slope are formalised in Eqs. (25) and (26), respectively.

Bullwhip Slope $=\operatorname{tg} \vartheta_{\text {ORVrR }}=\frac{K \sum_{i=1}^{K} p_{i} O R V r R_{i}-\sum_{i=1}^{K} p_{i} \sum_{i=1}^{K} \text { ORVrR }}{K \sum_{i=1}^{K} p_{i}^{2}-\left(\sum_{i=1}^{K} p_{i}\right)^{2}}$

Inventory Instability Slope $=\operatorname{tg} \vartheta_{I V r R}=\frac{K \sum_{i=1}^{K} I V r R_{i}-\sum_{i=1}^{K} p_{i} \sum_{i=1}^{K} I V r R_{i}}{K \sum_{i=1}^{K} p_{i}^{2}-\left(\sum_{i=1}^{K} p_{i}\right)^{2}}$
This technique provides a single value for each supply chain configuration and allows us to compare different responses of the system for different parameter settings.

Table 4 reports a framework of the adopted performance measurement system. Metrics are classified according to the time length of the measurement process, the data sources (echelon or whole supply chain), the scope concerned with the information released by the measure (local, referring to single echelon, and systemic, referring to the whole supply chain), the internal or customer benefit focus, the information content and the managerial implications in terms of costs.

\section{Design of the experiment and numerical results}

The second research question in the paper is to quantify the SSC response to variations of its operational parameters in terms of bullwhip reduction, inventory stability and customer service level. To do so, a boundary variation analysis is performed on lead time, demand smoothing forecasting factor, and proportional controller of the replenishment rule. The three parameters of the $(S, R)$ order policy for each echelon are tested at three levels (high, medium and low) according to a standard Latin Square Design (see Fig. 3). Cardinal numbers from 1 to 3 stand for the levels of the demand forecasting factor $\alpha$, Roman numbers for the levels of lead time $\lambda$, capital letters for the levels of the proportional controller $\beta$.

To set the numerical values for the experiments, we have sought for values employed in the related literature. Medium levels of lead time and demand smoothing forecasting factor, initial values of the state variables, safety stock factor, and the market demand pattern refer to the setting of Sterman's traditional supply chain model (Sterman, 1989). This setting was used in several relevant supply chain analyses, e.g. Wikner et al. (1991), Van Ackere et al. (1993), John et al. (1994), Crespo Márquez et al. (2004), Machuca and Barajas (2004), Jakšič and Rusjan (2008), or Wright and Yuan (2008). The matched proportional controller (Deziel and Eilon, 1967) values are chosen on the basis of $1 / \beta=\lambda+1$. This relation has been tested by several simulations and analytical environments and it presents an extremely well behaved dynamic response (Disney and Towill, 2006). The high and low values of the demand smoothing forecasting factor are the double and the half of Sterman's value, respectively. The high and low values of lead time are obtained as the extreme of a unit radius neighbourhood of the medium value.

In this study the safety stock factor is maintained constant throughout the experimental sets. The parameter value is set as in Sterman (1989) and Crespo Márquez et al. (2004). Since the aim of this paper is to analyse the SSC performance also by taking into account the customer service, we assess the benefits for customers, keeping constant the buffer capability to absorb market-related shocks. This assumption also relies on managerial con-

\begin{tabular}{|c|c|c|c|}
\hline & \multicolumn{3}{|c|}{$\boldsymbol{\lambda}$} \\
\hline $\boldsymbol{\alpha}$ & $\mathrm{I}$ & $\mathrm{II}$ & $\mathrm{III}$ \\
\hline 1 & $\mathrm{~A}$ & $\mathrm{~B}$ & $\mathrm{C}$ \\
\hline 2 & $\mathrm{~B}$ & $\mathrm{C}$ & $\mathrm{A}$ \\
\hline 3 & $\mathrm{C}$ & $\mathrm{A}$ & $\mathrm{B}$ \\
\hline
\end{tabular}

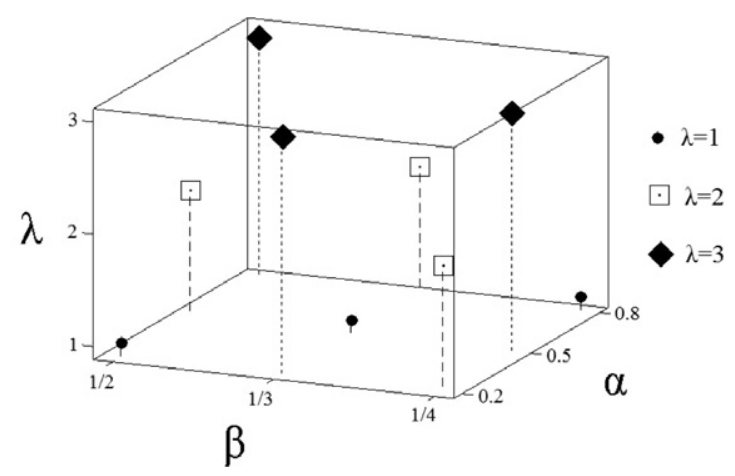

Fig. 3. Experimental design. 

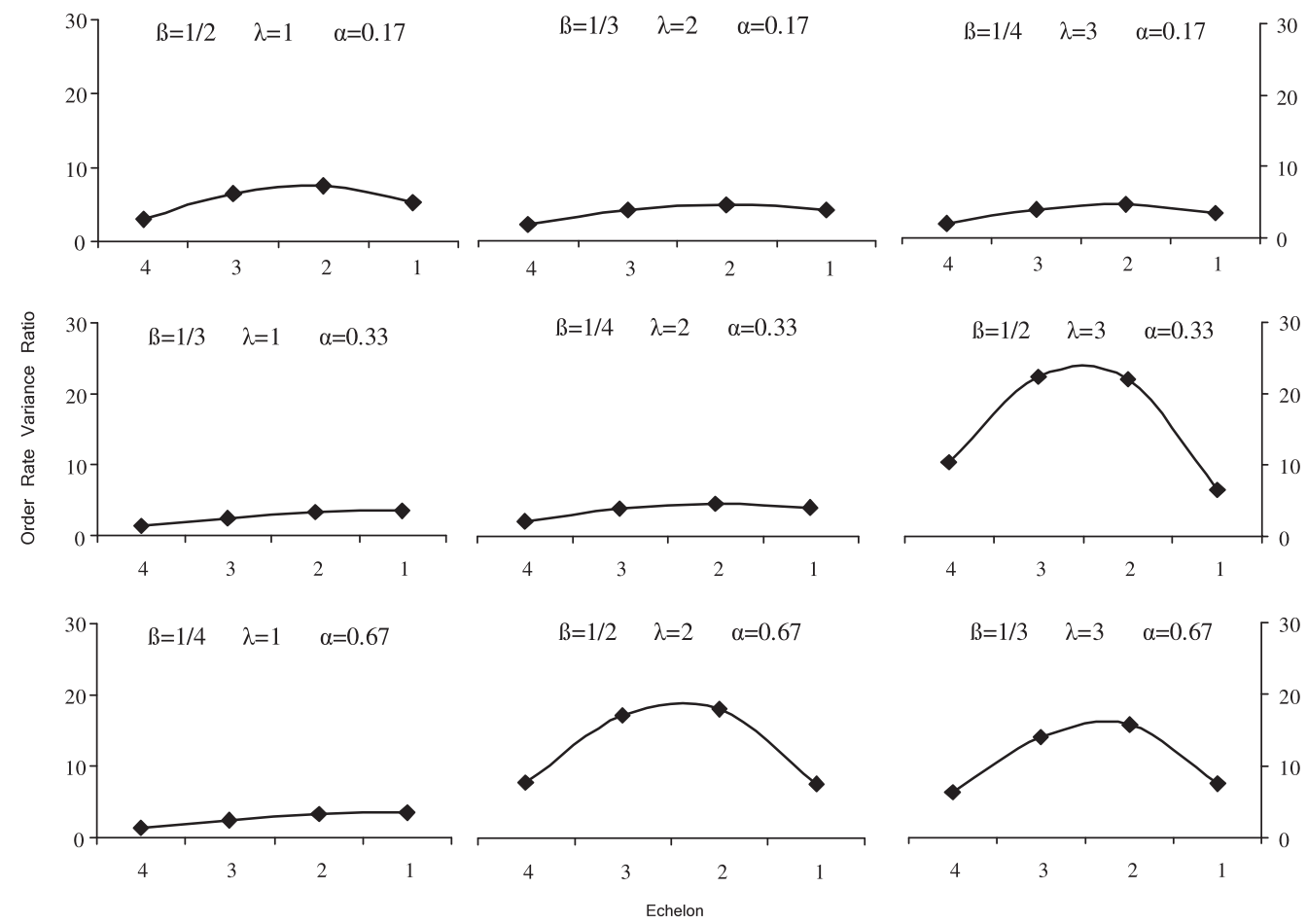

Fig. 4. Order Rate Variance Ratio.
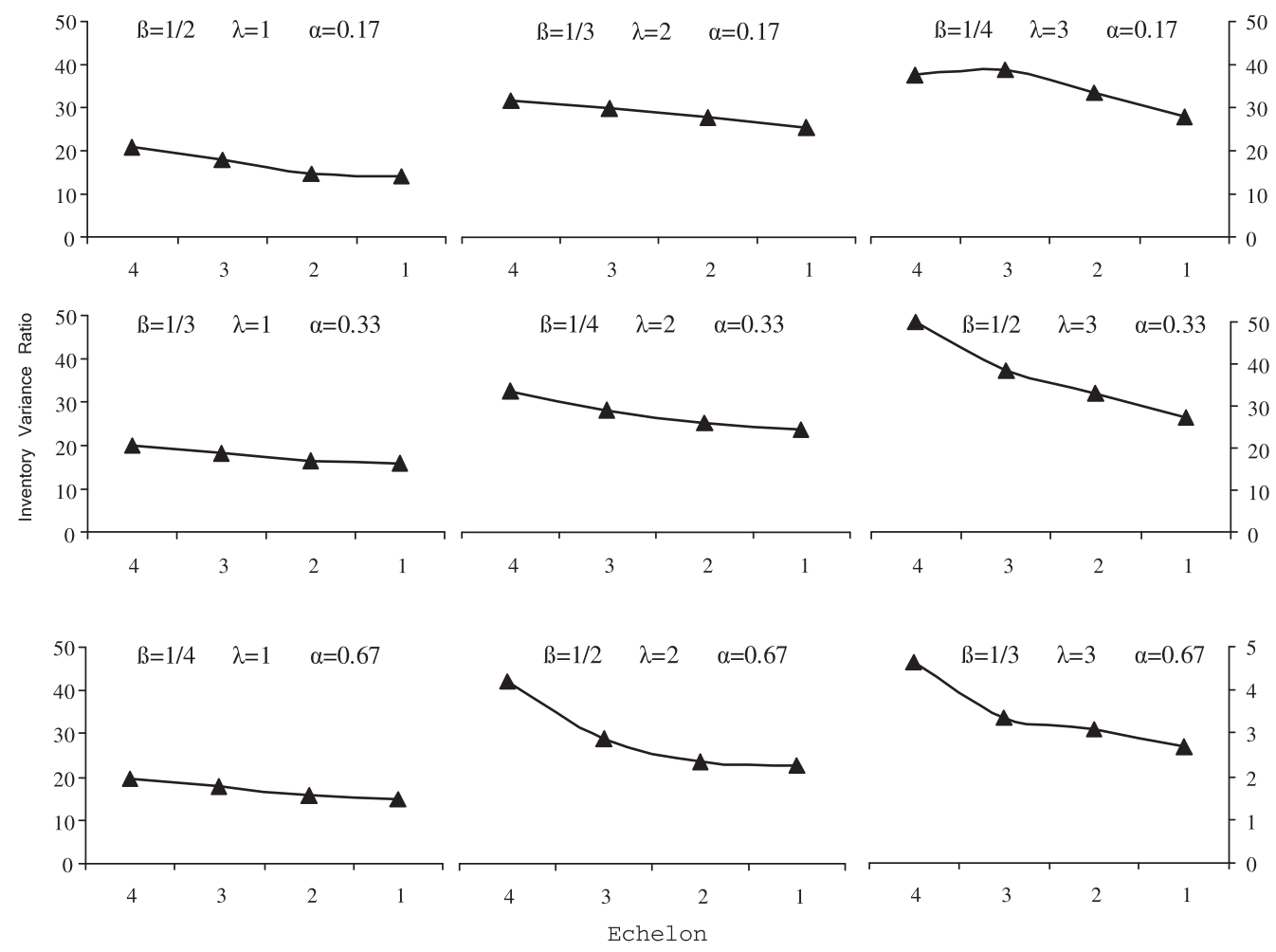

Fig. 5. Inventory Variance Ratio.

siderations, as often inventory investment is budget-constrained. Hadley and Whitin (1963) note that perhaps the most important real world constraints are budget restrictions on the amount that can be invested in inventory (Ghalebsaz-Jeddi et al., 2004). Besides, increasing the safety stock is always correlated to an increase in the service level (Graves and Willems, 2003; Disney et al., 2006).
The numerical experiments are performed under the following settings:

- The serial system is composed by four echelons, i.e. $K=4$.

- The initial values of the state variables are: $\left[W_{i}(0), I_{i}(0)\right.$, $\left.B_{i}(0)\right]=\left[\lambda_{i} d(0), \varepsilon_{i} d(0), 0\right] \forall i$. 
Table 5

Bullwhip slope, Inventory Instability Slope and the Average Fill Rate.

\begin{tabular}{llllll}
\hline \multicolumn{1}{l}{ Sets } & & & $\begin{array}{l}\text { Bullwhip } \\
\text { slope }\end{array}$ & $\begin{array}{l}\text { Inventory } \\
\text { instability slope }\end{array}$ & $\begin{array}{l}\text { Average } \\
\text { fill rate }\end{array}$ \\
\hline$\beta=1 / 2$ & $\lambda=1$ & $\alpha=0.17$ & 2.31 & -3.14 & 99.36 \\
$\beta=1 / 3$ & $\lambda=1$ & $\alpha=0.33$ & 0.91 & -1.71 & 98.00 \\
$\beta=1 / 4$ & $\lambda=1$ & $\alpha=0.67$ & 0.94 & -1.94 & 98.67 \\
$\beta=1 / 3$ & $\lambda=2$ & $\alpha=0.17$ & 0.99 & -1.78 & 86.98 \\
$\beta=1 / 4$ & $\lambda=2$ & $\alpha=0.33$ & 1.19 & -3.47 & 88.01 \\
$\beta=1 / 2$ & $\lambda=2$ & $\alpha=0.67$ & 4.70 & -8.53 & 90.61 \\
$\beta=1 / 4$ & $\lambda=3$ & $\alpha=0.17$ & 1.33 & -2.03 & 75.45 \\
$\beta=1 / 2$ & $\lambda=3$ & $\alpha=0.33$ & 5.84 & -8.42 & 79.25 \\
$\beta=1 / 3$ & $\lambda=3$ & $\alpha=0.67$ & 4.70 & -7.83 & 79.94 \\
\hline
\end{tabular}

- The lead time levels are $\lambda_{i}=[1,2,3] \forall i$.

- The demand smoothing forecasting factor varies over the values $\alpha_{i}=[0.17,0.33,0.67] \forall i$.

- The proportional controller is $\beta_{i}=[1 / 2,1 / 3,1 / 4] \forall i$.

- The safety stock factor is $\varepsilon_{i}=3 \forall i$.

- Numerical experiments are performed for a time length $T=100$.

- The solutions for the initial-value problem are approximated through Vensim PLE (Ventana Systems Inc., 2006). The EulerCauchy method with order of accuracy $\Delta t=0.25$ is adopted.

- The assumed demand $d(t)$ is a step-function demand shock. This demand patterns reproduces a sudden change from one state shift to another, also according to the aforementioned "shock lens" perspective (Towill et al., 2007) for the analysis of production-inventory systems. The demand $d$ is initialised at $d(0)=100$ units per time unit, until there is a pulse at $t=10$, increasing the demand value up to 200 units per time unit from $t=10$ on.

In the following, the numerical output of the experiments is presented. Data are collected and the metrics discussed in Section 3 are herein used to assess performance of the SSC. The Order Rate
Variance Ratio and Inventory Variance Ratio measures are plotted according to Dejonckheere et al.'s notation (Figs. 4 and 5).

The Bullwhip Slope, Inventory Instability Slope and the Average Fill Rate are reported in Table 5. Bullwhip Slope and Inventory Instability Slope are computed on echelons $i=2, i=3$ and $i=4$. Echelon $i=1$ is excluded from the inference due to unlimited raw material supply condition of the model.

Results from the statistical analysis, conducted using the Minitab software tool, on order rates, inventory levels and Average Fill Rates are reported in Table 6. Columns present the sources of variation (lead time $\lambda$, proportional controller $\beta$ and demand smoothing forecasting factor $\alpha$ ), the respective degrees of freedom (DF), the sum of squares (SS), and the mean squares (MS). The last two columns report the $F$ value, the statistic used to test that the effects of a factor are significant, and the $p$-value, the smallest level of significance that would lead to reject the hypothesis that a factor has a significant effect on a given variable (Montgomery, 2005).

The analysis of variance for Average Fill Rate reveals that lead time $\lambda$ is a significant factor for Average Fill Rate at $p<0.004$ level of significance, while the proportional controller $\beta$ and the demand smoothing forecasting factor $\alpha$ do not affect the mean value of this response variable. Lead time $\lambda$ is a significant source of variation also for order rates of all echelons, while the proportional controller $\beta$ and the demand smoothing forecasting factor $\alpha$ are not significant. The analysis of inventory levels variance shows a slight difference with respect to Average Fill Rate and order rate. The proportional controller $\beta$ and the demand smoothing forecasting factor $\alpha$ are still not significant. Lead time $\lambda$ is a significant source of variation for inventory levels of echelon $i=1,2,3$ but not for $i=4$.

\section{Discussion}

Numerical experiments quantify the benefits achieved through SSC, i.e. the removal of bullwhip effect. More specifically, the SSC

Table 6

Statistical analysis on order rates, inventory levels and Average Fill Rates (General Linear Model).

\begin{tabular}{|c|c|c|c|c|c|c|c|c|c|c|c|}
\hline Source of variation & DF & SS & MS & $F$ & $P$ & Source of variation & DF & SS & MS & $F$ & $p$ \\
\hline Order Rate $i=4$ & & & & & & Order Rate $i=3$ & & & & & \\
\hline$\lambda$ & 2 & 5.98476 & 2.9238 & 8237.3 & 0.000 & $\lambda$ & 2 & 23.5108 & 11.7554 & 702527.48 & 0.000 \\
\hline$\beta$ & 2 & 0.0057 & 0.0029 & 0.79 & 0.560 & $\beta$ & 2 & 0.0018 & 0.0009 & 54.91 & 0.018 \\
\hline$\alpha$ & 2 & 0.0116 & 0.0058 & 1.59 & 0.385 & $\alpha$ & 2 & 0.0001 & 0.0000 & 2.66 & 0.274 \\
\hline Error & 2 & 0.0073 & 0.0036 & & & Error & 2 & 0.0000 & 0.0000 & & \\
\hline Total & 8 & 5.8722 & & & & Total & 8 & 23.5128 & & & \\
\hline Order Rate $i=2$ & & & & & & Order Rate $i=1$ & & & & & \\
\hline$\lambda$ & 2 & 52.9847 & 26.4923 & 425351.5 & 0.000 & $\lambda$ & 2 & 94.141 & 47.071 & 3321574.56 & 0.000 \\
\hline$\beta$ & 2 & 0.0015 & 0.0007 & 11.83 & 0.078 & $\beta$ & 2 & 0.000 & 0.000 & 0.05 & 0.951 \\
\hline$\alpha$ & 2 & 0.0001 & 0.0000 & 0.43 & 0.698 & $\alpha$ & 2 & 0.000 & 0.000 & 0.88 & 0.531 \\
\hline Error & 2 & 0.0001 & 0.0001 & & & Error & 2 & 0.000 & 0.000 & & \\
\hline Total & 8 & 52.9863 & & & & Total & 8 & 94.141 & & & \\
\hline Inventory $i=4$ & & & & & & Inventory $i=3$ & & & & & \\
\hline$\lambda$ & 2 & 1539.8 & 769.9 & 5.95 & 0.144 & $\lambda$ & 2 & 2669.26 & 1334.63 & 20.47 & 0.047 \\
\hline$\beta$ & 2 & 1448.2 & 724.1 & 5.60 & 0.152 & $\beta$ & 2 & 465.47 & 232.73 & 3.57 & 0.219 \\
\hline$\alpha$ & 2 & 1263.1 & 631.6 & 4.88 & 0.170 & $\alpha$ & 2 & 456.76 & 228.38 & 3.50 & 0.222 \\
\hline Error & 2 & 258.8 & 129.4 & & & Error & 2 & 130.39 & 65.20 & & \\
\hline Total & 8 & 4510.1 & & & & Total & 8 & 3721.87 & & & \\
\hline Inventory $i=2$ & & & & & & Inventory $i=1$ & & & & & \\
\hline$\lambda$ & 2 & 4609.40 & 2304.70 & 30.34 & 0.032 & $\lambda$ & 2 & 7136.0 & 3568.0 & 58.80 & 0.017 \\
\hline$\beta$ & 2 & 429.68 & 214.84 & 2.83 & 0.261 & $\beta$ & 2 & 516.3 & 258.2 & 4.25 & 0.190 \\
\hline$\alpha$ & 2 & 391.77 & 195.89 & 2.58 & 0.279 & $\alpha$ & 2 & 454.4 & 227.2 & 3.74 & 0.211 \\
\hline Error & 2 & 151.92 & 75.96 & & & Error & 2 & 121.4 & 60.7 & & \\
\hline Total & 8 & 5582.77 & & & & Total & 8 & 8228.1 & & & \\
\hline \multicolumn{12}{|l|}{ Average Fill Rate } \\
\hline$\lambda$ & 2 & 552.695 & 276.347 & 253.79 & 0.004 & & & & & & \\
\hline$\beta$ & 2 & 8.533 & 4.267 & 3.92 & 0.203 & & & & & & \\
\hline$\alpha$ & 2 & 9.509 & 4.755 & 4.37 & 0.186 & & & & & & \\
\hline Error & 2 & 2.178 & 1.089 & & & & & & & & \\
\hline Total & 8 & 572.915 & & & & & & & & & \\
\hline
\end{tabular}


under unexpected changes in demand shows two main features regardless the parameter settings.

\subsection{The propagation of order rate variability is not exponential: the order stability property}

According to Dejonckheere et al.'s (2004) notation, bullwhip effect is present in case of a geometric increase of the Order Rate Variance Ratio values upstream in multi-echelon system. The curves plotted in Fig. 4 show a slight linear trend or a "bell" shape. The former behaviour indicates an outstanding reduction of the amplification in order rate, and the bell shape an initial growth of order amplification promptly smoothed. These results suggest the bullwhip dampening property of SSC under the studied parameter settings. More specifically, the curves indicate that the producer, who is the most affected among partners by the bullwhip phenomenon in traditional supply chains, is immune to the downstream members' order variability. The main reason for this behaviour is that echelon 1 is the only member of the chain that has full visibility of the whole supply chain. In traditional supply chains, an order placed by a downstream echelon is the main "information" adopted by the producer to manage its inventory. Therefore, a potential over-sizing of the order quantity is transmitted upstream in the form of distorted information about consumer demand. The coupling of over-sizing and information distortion, a typical problem of traditional supply chains, creates the irreparable demand amplification phenomenon. SSCs structurally decouple order from information. In SSCs the producer is able to avoid any potential amplification of downstream members' order variability through the full visibility of all processes in the chain.

In our study, the three settings reveal how the combination of high lead times and low smoothing factor could lead to a slight growth of order variability, but even in these cases the producer is still not affected by the demand amplification phenomenon. In the real business world, this implies that implementing a SSC means to materialise the advocated supply chain quality of the new millennium: operational and customer responsiveness. Definitely, the scalability quality of demand signal processing under Towill et al.'s (2007) shock lens is provided by the SSC.

\subsection{The negative slope for Inventory Variance Ratio: the inventory stability property}

Dejonckheere et al.'s curves for Inventory Variance Ratio reveal a peculiar phenomenon: The inventory stability transmission. For all parameter settings, the Inventory Variance Ratio curves have negative slopes (Table 5). This trend is in contrast with respect to the classical reaction of inventory to a violent alteration in demand signal. In general, one of the effects of unexpected variation in demand is the oscillation of inventory levels: as in the order rate amplification phenomenon, the inventory oscillation phenomenon is amplified upstream along the multi-echelon system as well. More specifically, this noxious effect occurs in traditional production-distribution supply chains. When this oscillation takes place, the Dejonckheere et al. curves of Inventory Variance Ratio show a steep rise. Our results show that for the SSC there is no inventory oscillation. From the authors' knowledge, SSC is the first case of multi-echelon production control system revealing this distinctive attribute. The negative slope for Inventory Variance Ratio identifies a progressive variability reduction of inventory levels in up-stream direction. The main reason for this behaviour concerns the different computation of the $S$ level with respect to the traditional structure or collaborative structure in which tiers only share information about the customer demand. In traditional and in demand information sharing structures, the discrepancy between current and target levels of net stock and pipeline stock tends to increase as we move up in the chain. With respect to these structures, in the SSC the discrepancy between the $S^{\prime}$ level and the actual inventory level is less intense because the order-up-to level takes into account the whole inventory system, as $S^{\prime}$ related to the overall amount of items in the inventories of the members of the chain. As a consequence, in SSC the discrepancy between the $S^{\prime}$ level and the actual inventory level reduces as we move up in the chain. These results confirm the previous considerations on the beneficial impact of full visibility of processes in the supply chain. The highest node of SSC (i.e. the producer) benefits from highly reduced holding costs, which are equal to or minor than the holding costs at the lowest node of the chains (i.e. the retailer's). SSC structurally avoids operational inefficiencies since the highest nodes in the chain do not suffer from information distortions, as in traditional configurations.

Summing up, results suggest that SSC responds to sudden change in demand by solving bullwhip effect and creating stability in inventories. The two previous considerations derive from a systemic analysis of the SSC. In the SSC, Bullwhip effect is generally solved, and inventory is always stabilised. However, analysing Fill Rate and the differences in Dejonckheere et al.'s representations of Order Rate Variance Ratio and Inventory Variance Ratio, we can extend our analysis and make the following considerations:

\subsubsection{The impact of lead time and safety stock on customer service} level

Analysing Average Fill Rate values, a difference can be observed for the three different settings of lead time. For an increase in $\lambda$, a deterioration of Fill Rate is observed, being the extreme case for $\lambda=3$, where $20-25 \%$ of customer demand is unfulfilled during the stock-out period (Table 5). This consideration is confirmed by the statistical analysis (see Table 6), according to which lead time is a factor that highly impacts on performance. By analysing Inventory Variance Ratio curves we can observe an analogous impact of increasing lead time on performance: Albeit the negative slope clearly shows the inventory stability property, the intercept of the curves, representative of the average magnitude of Inventory variability, increases with the lead time. Order Rate Variance Ratios show a similar trend. Despite no curve shows bullwhip effect, some of them present a "bell" shape, which is indicative of an initial growth of order amplification that, in the experimental set presenting this phenomenon, is later smoothed, regulated and stopped. The only family of curves in which we can always observe a very slight increase of Order Rate Variance Ratio is for the lowest level of factor $\lambda(\lambda=1)$. This confirms several studies on the impact of lead time and on the benefits provided by its compression (Wikner et al., 1991; Towill, 1996; Chen et al., 2000; Chatfield et al., 2004; Chandra and Grabis, 2005; Disney et al., 2006; Kim et al., 2006; Agrawal et al., 2009). In the SSC, although the problem of distortion and delay of information is solved, production-distribution lead time management continues to be a key factor for internal and customer benefits. Note that the effect of production-distribution lead time cannot be analysed without taking into consideration a further essential component of production inventory control: The safety stock level. Let us remember that we set the safety stock factor to be the same for all experiments. The experimental sets with $\lambda=1$ outperform the others not only for the intrinsic benefit provided by lead time compression, but also for the setting of the safety stock factor $\varepsilon$. For longer lead times, a larger safety stock is required to avoid shortage situations and assure high service level (Hax and Candea, 1984). For $\lambda=1$ and $\varepsilon=3$ safety stock assures more protection against shortages than the cases $\lambda=[2,3]$ and $\varepsilon=3$.

This result reminds us the thorny dilemma of inventory control: the compromise between too costly shortages and too expensive inventories. 
6.2.2. Proportional controller and exponential smoothing factor create an opposite trend between customer service and internal benefit measures for long lead time

By jointly analysing Average Fill Rate (Table 5) and Order Rate Variance Ratio (Fig. 5), we can observe the influence of proportional controller and demand smoothing forecasting factor variations on the SSC performance. The effect of the two factors is clearly lower than that of the lead time (confirmed by the statistical analysis in Table 6). Both $\alpha$ and $\beta$ act as "filters", being $\alpha$ the "external" filter and $\beta$ the "internal" filter. $\alpha$ filters the incoming demand, while $\beta$ smoothes the inventory and work in progress gaps. Under the shock lens, $\alpha$ attenuates the external shock per se, while $\beta$ mitigates the system's reaction to the shock. The demand smoothing forecasting factor and the proportional controller act as smoothers of a potential over-reaction to sudden changes in demand by suppliers, thus limiting the potential propagation of bullwhip shockwave along the supply chain. An excessive filtering of demand and order rate could impede to fulfil the customer demand in time (Cannella and Ciancimino, 2010). In this work, two experimental sets are paradigmatic of the filtering impact. By observing the set characterised by the parameters $\beta=1 / 4, \lambda=3$, $\alpha=0.2$, in which the proportional controller and the demand smoothing forecasting have the maximum smoothing action, the Bullwhip Slope value is rather low. This low value of slope (1.33) is indicative of intense bullwhip smoothing, despite the high level of lead time. On the other hand, for the same set the Average Fill Rate value is the worst among all numerical experiments. The set $\beta=1 / 2, \lambda=2, \alpha=0.8$ presents a higher Bullwhip Slope value (4.70), which is indicative of more intense bullwhip propagation. At the same time, an increment of $15 \%$ in Average Fill Rate is observed with respect to the set $\beta=1 / 4, \lambda=3, \alpha=0.2$.

To conclude, we can hypothesise that an opposite trend exists between customer service and internal benefit measures, and that this is due to the fact that the filtering action is more acute for long lead times. Therefore, in a SCC with long lead times, proportional controller and safety stock factor tuning has to be based on a context-related trade-off analysis between operational cost saving and backlog costs.

\section{Conclusions}

The aim of this paper was to analyse the operational response of the SSC. In the first part of the study, a new mathematical model of a SSC was presented. The supply chain model was then evaluated under a variety of performance measures and using a rigorous design of experiments. Finally, sound conclusions regarding the performance of the SSC were extracted. These are:

1. The order and inventory stability properties of SSC. SSC responds to violent changes in demand by resolving bullwhip effect and by creating stability in inventories. Results are indicative of bullwhip dampening of SSC under variations of the boundary conditions: The propagation of order rate amplification is not exponential in every parameter setting. Furthermore, for all simulations, the Dejonckheere et al.'s curves for Inventory Variance Ratio have a negative slope: SSC is characterised by a peculiar phenomenon of inventory stability transmission. Results suggest that the SSC is one of the most effective solutions to bullwhip and all the so-called plagues of Pandora's industrial box (Holweg et al., 2005).

2. The weight of lead time and safety stock on customer service level. When analysing Average Fill Rate values, a difference is observed for the three different settings of lead time. In the SSC, a long production-distribution lead time could significantly affect customer service level. If the length of distribution lead time is considerable, a high customer service level can be preserved through an increase in safety stock. Clearly, maintaining large safety stocks allows high flow rates, corresponding to a high customer service level, but raises holding costs. Furthermore, perishability and obsolescence of stored products have to be taken into consideration. This solution cannot be considered an absolute optimum: a trade off between holding and shortage costs is strongly needed. The result confirms the empirical study of Holweg et al. (2005): "Linking internal and external processes work well with relatively short distances between the echelons. What happens, though, if retailer and supplier are far apart? Suddenly, the inventory and lead time incurred in the transportation becomes a crucial element" (Holweg et al., 2005). In SSCs Towill's Time Compression Principle (1996) persists: Lead time management is and continues to be an aere perennius in operations management.

\section{Acknowledgements}

We wish to thank the referees for insightful comments on earlier versions of the paper. This research was funded by the Italian Ministry of University and Research, by the Portuguese Foundation for Science and Technology (Grant No. SFRH/BPD/68576/2010) and by the Autonomous Community of Andalusia (calls I/2010 and II/ 2010).

\section{References}

Aggelogiannaki, E., Doganis, P., Sarimveis, H., 2008. An adaptive model predictive control configuration for production-inventory systems. International Journal of Production Economics 114, 165-178.

Agrawal, S., Sengupta, R.N., Shanker, K., 2009. Impact of information sharing and lead time on bullwhip effect and on-hand inventory. European Journal of Operational Research 192, 576-593.

Akintoye, A., McIntosh, G., Fitzgerald, E., 2000. A survey of supply chain collaboration and management in the UK construction industry. European Journal of Purchasing and Supply Management 6, 159-168.

Anderson, D.L., Lee, H.L., 1999. Synchronized supply chains: the new frontier. In: Anderson, D.L. (Ed.), Achieving supply chain excellence through technology. Montgomery Research, San Francisco, pp. 112-121.

Barratt, M., Oliveira, A., 2001. Exploring the experiences of collaborative planning initiatives. International Journal of Physical Distribution and Logistics Management 31, 266-289.

Bayraktar, E., Lenny Koh, S.C., Gunasekaran, A., Sari, K., Tatoglu, E., 2008. The role of forecasting on bullwhip effect for E-SCM applications. International Journal of Production Economics 113, 193-204.

Beamon, B.M., Chen, V.C.P., 2001. Performance analysis of conjoined supply chains. International Journal of Production Research 39, 3195-3218.

Boute, R.N., Disney, S.M., Lambrecht, M.R., Van Houdt, B., 2007. An integrated production and inventory model to dampen upstream demand variability in the supply chain. European Journal of Operational Research 178, 121-142.

Cachon, G., Fisher, M., 2000. Supply chain inventory management and the value of shared information. Management Science 46, 1032-1048.

Caloiero, G., Strozzi, F., Zald́ivar Comenges, J.M., 2008. A supply chain as a series of filters or amplifiers of the bullwhip effect. International Journal of Production Economics 114, 631-645.

Cannella, S., Ciancimino, E., 2010. On the bullwhip avoidance phase: supply chain collaboration and order smoothing. International Journal of Production Research 48, 6739-6776.

Cannella, S., Ciancimino, E., Márquez, A.C., 2008. Capacity constrained supply chains: a simulation study. International Journal of Simulation and Process Modelling 4, 139-147.

Cannella, S., Ciancimino, E., Canca Ortiz, J.D., Setchi, R., 2010a. Production inventory and enterprise system implementation: an ex-ante no-cost based evaluation. Lecture Notes in Business Information Processing 47, 291-303.

Cannella, S., Ciancimino, E., Framinan, J.M., Disney, S.M., 2010b. The four supply chain archetypes. Universia Business Review, 26.

Chaharsooghi, S.K., Heydari, J., 2010. LT variance or LT mean reduction in supply chain management: which one has a higher impact on SC performance? International Journal of Production Economics 124, 475-481.

Chandra, C., Grabis, J., 2005. Application of multi-steps forecasting for restraining the bullwhip effect and improving inventory performance under autoregressive demand. European Journal of Operational Research 166, 337-350.

Chatfield, D.C., Kim JG Harrison, T.P., Hayya, J.C., 2004. The bullwhip effect - impact of stochastic lead time, information quality, and information sharing: a simulation study. Production and Operations Management 13, 340-353. 
Chen, Y.F., Disney, S.M., 2007. The myopic order-up-to policy with a proportional feedback controller. International Journal of Production Research 45, 351-368.

Chen, L., Lee, H.L., 2009. Information sharing and order variability control under a generalized demand model. Management Science 55, 781-798.

Chen, Y.F., Drezner, Z., Ryan, J.K., Simchi-Levi, 2000. Quantifying the bullwhip effect in a simple supply chain: the impact of forecasting, lead times, and information. Management Science 46, 436-443.

Ciancimino, E., Cannella, S., 2009. Modelling the bullwhip effect dampening practices in a limited capacity production network. Lecture Notes in Business Information Processing 20, 475-486.

Ciancimino, E., Cannella, S., 2011. Supply chain modelling and analysis: an application of latin square to a repeated coupling of non-linear differential equations. International Journal of Logistics Systems and Management 9, 268279

Ciancimino, E., Cannella, S., Canca Ortiz, J.D., Framinan, J.M., 2009. Supply chain multi-level analysis: two bullwhip dampening approaches [Análisis multinivel de cadenas de suministros: dos técnicas de resolución del efecto bullwhip]. Revista de Métodos Cuantitativos para la Economíla y la Empresa 8, 7-28.

Clark, A.J., Scarf, H., 1960. Optimal policies for a multi-echelon inventory problem. Management Science 6, 475-490.

Coleman, J., 2010. Extending supply chain synchronisation to upstream tiers: a collaborative approach illustrated with an automotive case study. International Journal of Networking and Virtual Organisations 7, 257-271.

Crespo Márquez, A., Bianchi, C., Gupta, J.N.D., 2004. Operational and financial effectiveness of e-collaboration tools in supply chain integration. European Journal of Operational Research 159, 348-363.

DeCroix, G.A., 2006. Optimal policy for a multiechelon inventory system with remanufacturing. Operations Research 54, 532-543.

Dejonckheere, J., Disney, S.M., Lambrecht, M.R., Towill, D.R., 2002. Transfer function analysis of forecasting induced bullwhip in supply chains. International Journal of Production Economics 78, 133-144.

Dejonckheere, J., Disney, S.M., Lambrecht, M.R., Towill, D.R., 2003. Measuring and avoiding the bullwhip effect: a control theoretic approach. European Journal of Operational Research 147, 567-590.

Dejonckheere, J., Disney, S.M., Lambrecht, M.R., Towill, D.R., 2004. The impact of information enrichment on the Bullwhip effect in supply chains: a control engineering perspective. European Journal of Operational Research 153, 727750.

de Leeuw, S., Fransoo, J., 2009. Drivers of close supply chain collaboration: one size fits all? International Journal of Operations and Production Management 29, 720-739.

Derrouiche, R., Neubert, G., Bouras, A., 2008. Supply chain management: a framework to characterize the collaborative strategies. International Journal of Computer Integrated Manufacturing 21, 426-439.

Deziel, D.P., Eilon, S., 1967. A linear production-inventory control rule. Production Engineer 43, 93-104.

Disney, S.M., Lambrecht, M.R., 2008. On replenishment rules, forecasting, and the bullwhip effect in supply chains. Foundations and Trends in Technology, Information and Operations Management 2, 1-80.

Disney, S.M., Towill, D.R., 2002. A discrete transfer function model to determine the dynamic stability of a vendor managed inventory supply chain. International Journal of Production Research 40, 179-204.

Disney, S.M., Towill, D.R., 2003. On the bullwhip and inventory variance produced by an ordering policy. Omega, the International Journal of Management Science 31, 157-167.

Disney, S.M., Towill, D.R., 2006. A methodology for benchmarking replenishmentinduced bullwhip. Supply Chain Management 11, 160-168.

Disney, S.M., Naim, M.M., Potter, A., 2004a. Assessing the impact of e-business on supply chain dynamics. International Journal of Production Economics 89, 109118

Disney, S.M., Towill, D.R., Van De Velde, W., 2004b. Variance amplification and the golden ratio in production and inventory control. International Journal of Production Economics 90, 295-309.

Disney, S.M., Farasyn, I., Lambrecht, M.R., Towill, D.R., Van De Velde, W., 2006. Taming the bullwhip effect whilst watching customer service in a single supply chain echelon. European Journal of Operational Research 173, 151-172.

Disney, S.M., Lambrecht, M.R., Towill, D.R., Van De Velde, W., 2007. Controlling bullwhip and inventory variability with the golden smoothing rule. European Journal of Industrial Engineering 1, 241-265.

Dong, L., Lee, H.L., 2003. Optimal policies and approximations for a serial multiechelon inventory system with time-correlated demand. Operations Research 51, 969-980.

Fawcett, S.E., Magnan, G.M., McCarter, M.W., 2008. Benefits, barriers, and bridges to effective supply chain management. Supply Chain Management 13, 35-48.

$\mathrm{Fu}$, Q., Zhu, K., 2010. Endogenous information acquisition in supply chain management. European Journal of Operational Research 201, 454-462.

Ghalebsaz-Jeddi, B., Shultes, B.C., Haji, R., 2004. A multi-product continuous review inventory system with stochastic demand, backorders, and a budget constraint. European Journal of Operational Research 158, 456-469.

Gonçalves, P., Hines, J., Sterman, J., 2005. The impact of endogenous demand on push-pull production system. System Dynamics Review 21, 187-216.

Graves, S.C., Willems, S.P., 2003. Supply chain design: Safety stock placement and supply chain configuration. In: de Kok, A.G., Graves, S.C. (Eds.), Handbooks in OR\&MS, vol. 11. Elsevier, Amsterdam;, pp. 95-132.

Gunasekaran, A., Ngai, E.W.T., 2009. Modeling and analysis of build-to-order supply chains. European Journal of Operational Research 195, 319-334.
Hadley, G., Whitin, T.M., 1963. Analysis of Inventory Systems. Prentice-Hall, Englewood Cliffs.

Hahn, C.K., Duplaga, E.A., Hartley, J.L., 2000. Supply-chain synchronization: lessons from hyundai motor company. Interfaces 30, 32-45.

Hax, A.C., Candea, D., 1984. Production and Inventory Management. Prentice-Hall, Englewood Cliffs.

Holt, C.C., Modigliani, F., Muth, J.F., Simon, H.A., 1960. Planning Production Inventories and Work Force. Prentice-Hall, Englewood Cliffs.

Holweg, M., Disney, S.M., 2005. The evolving frontiers of the bullwhip problem. In: Proceeding of EUROMA Conference, pp. 707-716.

Holweg, M., Disney, S.M., Holmström, J., Småros, J., 2005. Supply chain collaboration: making sense of the strategy continuum. European Management Journal 23, 170-181.

Hosoda, T., Disney, S.M., 2006. On variance amplification in a three-echelon supply chain with minimum mean square error forecasting. Omega, the International Journal of Management Science 34, 344-358.

Ingalls, R.G., Foote, B.L., Krishnamoorthy, A., 2005. International Journal of Simulation and Process Modelling 1, 90-110.

Jakšič, M., Rusjan, B., 2008. The effect of replenishment policies on the bullwhip effect: a transfer function approach. European Journal of Operational Research 184, 946-961.

John, S., Naim, M.M., Towill, D.R., 1994. Dynamic analysis of a WIP compensated decision support system. International Journal of Management Systems Design 1, 283-297.

Kauremaa, J., Småros, J., Holmström, J., 2009. Patterns of vendor-managed inventory: Findings from a multiple-case study. International Journal of Operations and Production Management 29, 1109-1139.

Kelepouris, T., Miliotis, P., Pramatari, K., 2008. The impact of replenishment parameters and information sharing on the Bullwhip effect: a computational study. Computers and Operations Research 35, 3657-3670.

Kim, I., Springer, M., 2008. Measuring endogenous supply chain volatility: beyond the bullwhip effect. European Journal of Operational Research 189, 172-193.

Kim, J.G., Chatfield, D., Harrison, T.P., Hayya, J.C., 2006. Quantifying the bullwhip effect in a supply chain with stochastic lead time. European Journal of Operational Research 173, 617-636.

Lalwani, C.S., Disney, S.M., Towill, D.R., 2006. Controllable, observable and stable state space representations of a generalized order-up-to policy. International Journal of Production Economics 101, 172-184.

Lee, H.L., 2000. Creating value through supply chain integration. Supply Chain Management Review 14, 30-36.

Lee, H.L., 2004. The triple-A supply chain. Harvard Business Review 82, 102-113.

Lee, H.L., 2010. Taming the bullwhip. Journal of Supply Chain Management 46, 7.

Lee, H.L., Padmanabhan, V., Whang, S., 1997. Information distortion in a supply chain: the bullwhip effect. Management Science 43, 546-558.

Lee, H.L., Padmanabhan, V., Whang, S., 2006. The bullwhip effect: reflections. In: Carranza Torres, O., Villegas Morán, F. (Eds.), The Bullwhip Effect in Supply Chains, Palgrave (UK-USA), pp. 1-14.

Lyu, J., Ding, J.-H., Chen, P.-S., 2010. Coordinating replenishment mechanisms in supply chain: from the collaborative supplier and store-level retailer perspective. International Journal of Production Economics 123, 221-234.

Machuca, J.A.D., Barajas, R.P., 2004. The impact of electronic data interchange on reducing bullwhip effect and supply chain inventory costs. Transportation Research Part E: Logistics and Transportation Review 40, 209-228.

Magee, J.F., 1958. Production Planning and Inventory Control. McGraw-Hill, New York.

Makridakis, S., Andersen, A., Carbone, R., Fildes, R., Hibon, M., Lewandowski, R. Newton, J., Parzen, R., Winkler, R., 1982. The accuracy of extrapolation (time series) methods: results of a forecasting competition. Journal of Forecasting 1, 111-153.

McLaren, T., Head, M., Yuan, Y., 2002. Supply chain collaboration alternatives: understanding the expected costs and benefits. Internet Research 12, 348-364.

Montgomery, D.C., 2005. Design and Analysis of Experiments. Wiley, New York.

Ouyang, Y., 2007. The effect of information sharing on supply chain stability and the bullwhip effect. European Journal of Operational Research 182, 1107-1121.

Ouyang, Y., Daganzo, C., 2008. Robust tests for the bullwhip effect in supply chains with stochastic dynamics. European Journal of Operational Research 185, 340 353.

Pramatari, K., 2007. Collaborative supply chain practices and evolving technological approaches. Supply Chain Management 12, 210-220.

Riddalls, C.E., Bennett, S., Tipi, N.S., 2000. Modelling the dynamics of supply chains. International Journal of Systems Science 31, 969-976.

Sahin, F., Robinson Jr., E.P., 2005. Information sharing and coordination in make-toorder supply chains. Journal of Operations Management 23, 579-598.

Sarimveis, H., Patrinos, P., Tarantilis, C.D., Kiranoudis, C.T., 2008. Dynamic modeling and control of supply chain systems: a review. Computers and Operations Research 35, 3530-3561.

Shang, J.S., Li, S., Tadikamalla, P., 2004. Operational design of a supply chain system using the Taguchi method, response surface methodology, simulation, and optimization. International Journal of Production Research 42, 3823-3849.

Simatupang, T.M., Sridharan, R., 2008. Design for supply chain collaboration. Business Process Management Journal 14, 401-418.

Springer, M., Kim, I., 2010. Managing the order pipeline to reduce supply chain volatility. European Journal of Operational Research 203, 380-392.

Squire, B., Cousins, P.D., Lawson, B., Brown, S., 2009. The effect of supplier manufacturing capabilities on buyer responsiveness: the role of collaboration. International Journal of Operations and Production Management 29, 766-788. 
Stadtler, H., 2009. A framework for collaborative planning and state-of-the-art. OR Spectrum 31, 5-30.

Sterman, J., 1989. Modeling managerial behavior: misperceptions of feedback in a dynamic decision making experiment. Management Science 35, 321-339.

Swaminathan, J.M., Tayur, S.R., 2003. Models for supply chains in E-business. Management Science 49, 1387-1406.

Towill, D.R., 1996. Time compression and supply chain management - a guided tour. Supply Chain Management 1, 15-27.

Towill, D.R., Zhou, L., Disney, S.M., 2007. Reducing the bullwhip effect: looking through the appropriate lens. International Journal of Production Economics 108, 444-453.

Van Ackere, A., Larsen, E.R., Morecroft, J.D.W., 1993. Systems thinking and business process redesign: an application to the beer game. European Management Journal 11, 412-423.

Vereecke, A., Muylle, S., 2006. Performance improvement through supply chain collaboration in Europe. International Journal of Operations and Production Management 26, 1176-1198.

Verstrepen, S., Cools, M., Cruijssen, F., Dullaert, W., 2009. A dynamic framework for managing horizontal cooperation in logistics. International Journal of Logistics Systems and Management 5, 228-248.
Wang, J.-L., Kuo, J.-H., Chou, S.-y., Wang, S.-Z., 2010. A comparison of bullwhip effect in a single-stage supply chain for autocorrelated demands when using correct, MA, and EWMA methods. Expert Systems with Applications 37, 4726-4736.

Warburton, R.D.H., Disney, S.M., 2007. Order and inventory variance amplifications: the equivalence of continuous and discrete time analyses. International Journal of Production Economics 110, 128-137.

Whang, S., 1995. Coordination in operations: a taxonomy. Journal of Operations Management 12, 413-422.

Wikner, J., Towill, D.R., Naim, M., 1991. Smoothing supply chain dynamics. International Journal of Production Economics 22, 231-248.

Wright, D., Yuan, X., 2008. Mitigating the bullwhip effect by ordering policies and forecasting methods. International Journal of Production Economics 113, 587597.

Yu, M.-M., Ting, S.-C., Chen, M.-C., 2010. Evaluating the cross-efficiency of information sharing in supply chains. Expert Systems with Applications 37, 2891-2897.

Zhang, X., 2004. The impact of forecasting methods on the bullwhip effect. International Journal of Production Economics 88, 15-27.

Zipkin, P.H., 2000. Foundations of Inventory Management. McGraw-Hill, New York. 